Finalliza con la Segunda Parte que se inserta, la publicación de la tesis "MORAL" $\mathrm{Y}$ "VIDA" EN FEDERICO NIETZSCHE, presentada por Don José Russo Delgado, para optaz el grado de Doctor en Fllosolía.

SEGUNDA PARTE

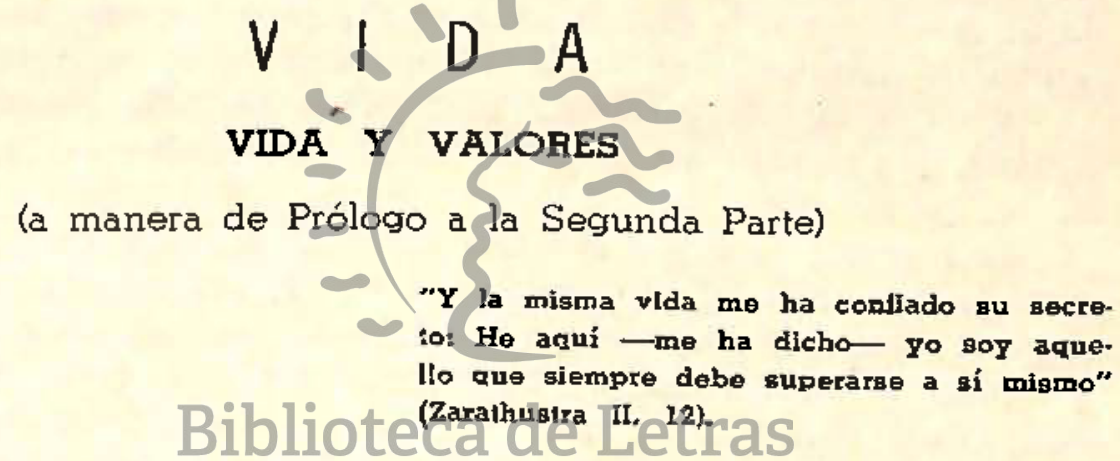

Ni tan manifiesta quểodesarime crivestróamor,enstan oculta que de sanime nuestra sabuduría, así es. Tiene todos los nombres y ninguno, juguetona. "mujer en todo", miente siempre y a veces muestra su hos. tilidad y sus garras cuando mejor ama, como en el caso de nuestro Nietzsche.

El "Ser", ese enorme cascarón, vacío interesa sólo a los "señores idólatras del concepto", los semisacerdotes, los filósofos, los enfermos de "egiptismo" para los que cambio, movimiento, juego: devenir, son una refutación. Pero el "Ser" sólo puede ser imaginado como Vida. Nietzsche rechaza los conceptos sin imagen, porque él, poeta y filósafo y filósofo poeta, sabe que en ellos ya la vida está disminuída, empalidecida. Los conceptos sólo en cuanto los podamos imaginar que sólo la imagen tlene vida, que la ausencia de la imagen es la ausencia de la vida del concepto, de la vivificación del concepto. La imagen es pues vida y la vida, imagen, imagen del Ser, yerto esposo de esta joven viu. da desposada nuevamente con Federico Nietzsche, con el filósofo poe- 
ta Federico Nietzsche $y$ en divina poliandría con todos los filósolos crea dores de valores.

Inasible y juguetona, huyendo de sí mísma y retornando a si misma, siempre gustando de dominar $y$ de ser dominada, de ser dominada por una de sus creaciones: el hombre, el-hombre filósofo, el filósofo poeta, desea también ella ser creada, su máxima recreación es esta de ser creada y recreada por el filósolo que es Nielzsche, por el filósofo del porvenir que anuncia Nietzsche.

No tiene nombre pero tiene lodos los nombres $y$ he aqui el que le dá este su dorninador: "Voluntad de dominio", así la llama, así la domina con esta denominación del dominio. Y ella gusia de dominar y de ser dominada. Y es porque es rica, que no tiene un sólo nombre y los tiene todos: puede ser llamada de mil maneras, quiere ser domina. da de mil maneras y una de ellas es precisamente con este nombre "Voluntad de dominio" con que la denomina su solitario amante.

$Y$ no se la puede juzgar: sólo puede ser juez quien no ama lo suficiente, y entonces ya no debe serlor los jueces serán los únicos en no ser perdonados.

Es mujer y, aunque sea una locuela, no debe ser tratada con descortesía que sería la más grave ofensa. Y, iha recibido tantas!: Sacerdotes, filósofos, moralistas, jla han ofendido tantas vecesl

Más he aquí al amado que llegà que sabe como nombrarla, que sabe como perserguirla, que goza en perseguir a la eternamente huidiza que quiere sergllamadain dominadaedectantas maneras y que no debe recibir la afrenta de un juicio el que sólo sirve para revelar a un hombre: al suficienterrente rico para amar a una mujer así o el resentido e irritado por su inasibilidad y sus desvíos, que la aborrece. Ella conoce al que pretende conocerla juzgándola: en estos juicios aparece el grado en que la tiene, la domina, la posee el juzgador. Nos revela la mezquindad del alma del que se atreve a condenar a la bella, inquietante, misteriosa, siempre presente. En la vehemencia para juzgar y condenar, la amada viviente en nosotros mismos, la siempre presente e inasible reconoce la incapacidad de amar.

La conciencia, diabólica servidora de la vida cuya historia es contraria a la del ángel caído -es una sierva sublevada que usurpa el poder- ha sido colocada por los señores filósofos como fiscal de todos los jueces que han querido condenar. Dios, que ha sido su gran exageración, ha condenado también la vida. Pero - ya Stendhal ha dicho que la única excusa de Dios es que no existe- este Dios no existe. La vida, la locuela, la única es la que juega a ser Dios y a dejar de serlo. 
La siempre igual y siempre diferente a sí misma no sólo "tiene demasiado valor para tener precio", sino que tiene demasiado valor para tener un valor. Antes bien es ella la que valora, pero no juzgando, sino jugando, jugando a elevarse sobre sí misma y los valores son las columnas y escalas hechas de ella misma por las que trepa sobre sí. Gusta de los colores y de los gustos por los colores y de la lucha por los gustos y por los colores.

Pero no ha creado desde un momento de la eternidad para siempre estos valores: no podría gozar de sus juguetes, si no pudiera romper sus juguetes; no subiría por escalas y columnas -es tan vivaz, le gusta tanto trepar- sino pudiera después destrozar lo constituído y re comenzar siempre su embriagador juego infinito.

Ha sido al llegar a la columna hombre - una columna también, también un escalón- que ha querido enfrentarse a si, que ha querido ocultarse $\mathrm{y}$ embellecerse $\mathrm{y}$ ser hallada. Ha sido a través de esta columna, de este escalón del cuerpo humano, tan misterioso, columna de todo el pasado, escalón hacia el porvenir, síntesis del devenir todo, una historia, siempre nueva scbre si misma, una denominación también, siempre nueva de sí.

La materia, uno de sus nombres menos afortunados, demasiado seco, seco, tieso y feo. fOhl ¡Felizmente no lo ha soportado mucho tiempcl. Y han sido los menos amados quienes la han llamado así. Pero el cuerpo del hombre, el amado cuerpo del hombre que quisiera elevarse con el conocimiento, este cuerpo que ha togrado su mayor elevación

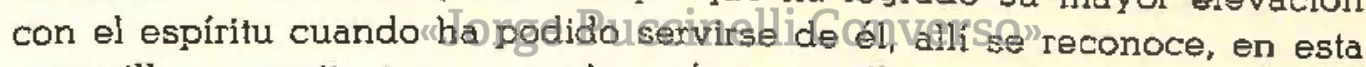
maravillosa arquitectura - mucho más maravillosa de lo que pueda ser nunca la que nunca ha sido, el alma- arquitectura del dominio que quiere el dominio.

$Y$ el más alto dominio lo ha conseguido esta valiente amazona de la vida combatśendo sobre nobles corceles, los valores. Guerrera, de la infantería de lo biológico, ha jugado mejor, se ha elevado más, ha dominado más en la caballería de lo vitel, en la creación y juego de los valores.

Mentira que los haya creado ese gruñón $\ominus$ inexistente juez severo y que estén alli, definitivos, en su trasmundo pálido, más pálido que el del gran creador de trasmundos, Platón, el gran mentiroso, dedicados a insultarla, denigrarla, condenarla. (Bastante caro está haciendo pagar ella esla loca afrenta).

Los valores son su recreo, la creación primero de muchos hombres que se han llamado raza, pueblo, nación $\mathrm{Y}$ después de un hombre. Y 
se espera la mayor de las creaciones de ese su preferido, sólo conocido oor el historiador del futuro; de ese que va a venir y que Nietzsche Zàrathustra anuncia, del Superhombre.

Y no sólo los valores han sido hechos por su forma hombre, sino que mediante ellos se ha dado forma a sí misma. Mentirosa, inasible, siempre ozulta, siempre cambiante, se ha dejado llamar para olvidar después su nombre; se ha dejado apresar y ha sido la cárcel y el carcelero y la libertad para escurrirse por fin.

Pero los valores son ella y el hombre es ella y ella es el dominio. Con los valeres buscaba el dominio y jugaba al dominio, $Y$ cuando los que la temían, ios que no sabían sobrepasar con su amor la desconiißnza, los inspirados por su hermana menor, enferma y envidiosa, la ctacaban, ellos eran quienes sufrían más sutriendo ella en ellos.

$Y_{1}$ ella es la no muerte, la muerte de la muerte, porque ella es creación, vale decir evaluación, interpretación del dominio.

Pero en su huida de si misma crea a esta hermana enferma llena de ojeriza que tambiér quiere crear y lo hace moviendo al gran juez cruñón que le sirve de títere y obtiene estos pálidos muñecos y todos juntos juzgan y condenan a la innombrable, a la múltiple, a la que lo venetra todo. Pero he aquí que llega el mostachudo gran abogado de la calumniada y enseña a los pálidos muñecos a bailar para reconciliarlos así con la acusada.

Porque ella, quebos muerteddela muertepno "es", pues la muerte muere en la valuación a síqquénndihayosefesing, valer, esto es: el valer es el único ser.

Ella se crea elernamente a sí misma al evaluarse. Ni hay "sustancia", ni ella es una "cosa en si". "En si" no hay sino su locura, su aliena. ción, su siempre ser otra. No hay una "sustancia que deviene", sino un devenir, una pasión, un apasionamiento de la voluntad de poder.

Porque el hombre ha sido este gran millonario pródigo, pronto arruinado, que ha puesto un sentido en las cosas, que,artista, ha llenado el cascarón vacío de adornos multicolores y se ha ocultado después Y ha ocultado su generosidad.

Hijos preferidos de la vida y del hombre, hermanos pues, los valores viven en perpetua lucha por poseer la heredad de sus pedres. Nietzsche nos hace la defensa del más bello, del preferido de la madre y. $\sin$ embargo,. el menos afortunado, contra aquel otro que cometíó ese máximo e imposible matricidio. Como en el fondo son tan diferentes el despojado quiere un gobierno alegre con fiestas y cantos y bailes $y$ bellas locuras,pero el matricida quiere siempre seriedad y castigos. 
Fuertes y vigorosos, nuestra humanidad y nuestro amor no admiten que puedan morir todos y entonces la vida tener otros que lucharán siempre entre sí. Vivos hijos de la vida, con un nacimiento y una muerte, los más presiados hijos del hombre, los valores. Ningún "apriori", ningún "intemporal", "inespacial". Símbolos y nombres del juego de la vida para superarse en el hombre y el Superhombre, esto son los valores.

Menos aún, una tabla apriorística, como no sea la creada por una formidable fuorza, por una férrea voluntad capaz de imprimirse por cien mil años en la historia. Y no importa lo que nos digan los filósofos del siglo XX los del neo-positivismo fenornenólogico del Antinietzsche; ¡Hechos! ¡Hechosi. "Pues no hay hechos, sino interpretaciones". Al lado del filósofo que describe el pasado, lo ya creado, está esa forma superior del que crea perspectivas para el porvenir. (Por las que después circulan atareados los hombres de acción). Contra el positivismo,

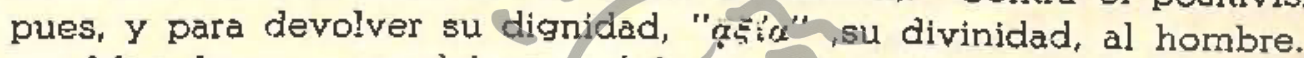

Mas, forma parte del error útil al hombre el creer que los valores y las tablas de valores de cada époça o pueblo son eternas o dadas por algún Dios, así obran más eficazmente.

$Y$ no pidáis a los valores un sígnificado: son demasiado ricos $Y$ demasiado sabios para dar sus razones, han aprendido de su madre a escabullir todas las razones.

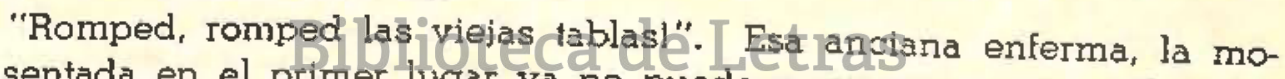
ral, sentada en el priner lugar ya no pusde provocar nuestra adhesión. ¡Filósofos, a los bartosge lauterta de los váfores" "también es redonda".

Hombre, hombre "digno", recobra tu dignidad. Obliga a las cosas a renacer y a ser por tu amor de creador. Con tu gran instrumento vivo, el espiritu, sube, vida, a tu mayor altura en el acto de la creación, Y no permitáis que del instrumento se haga una prisión; no dejemos que con el oro del espíritu se forien cadenas - jiSiempre son cadenas!! - para apresar la vida.

He aquí las antiguas evaluaciones que ya no pueden sostenerse y que se han hecho cada vez más imposibles. He aquí el hombre aturdido, debilitado por la falta de sentido que le rodea, aterido por el frío de la nada, de la gran muerte que desorbita su mirada y destruye sus esperanzas. ¡Destruíd esa nada, vosotros, creadores del porvenir! Vosotros, los más poderosos, los mayormente vivientes, lograd para vuestra poderosa vida, para vuestro vivo poder, la más viva, potente y alta ex- 
presión. Dad muerle a la muerte de mil modos, vosotros creadores deì porvenir, dad muerte a la muerte en mil alegres tormas.

No viváis con tablas a medio construir, oh hombres, porque revelan Y provocan el gran cansancio y la gran cobardía, precursores de la gran nada.

Ya sabéis que la tarea no es transportar montañas sino construirlas. ¿Conocéis el nombre del material más duro que debéis trabajar?. Pasado, así se llama. Debéis salvar esa inmensa masa de obsidiana al otor. garle un nuevo sentido.

Vida, entrégale a tu divino juego. Hazte pesador, balanza $y$ pesas, vida. Quizá con ellas al apreciarte te desprecies, pero se te conoce en que tu sabes del gran amor junto al gran desprecio. Allí donde el débil quiere conservar porque quiere seguridad, alli el más vigoroso busca la inseguridad y la vulnerabilidad en las que encuentra su ma. yor dicha. En la creación, siempre en la creaclón que es tambión muerte $y$ muerte de la muerte.

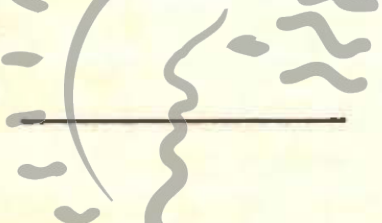

I.- LA VOLUNTAD DE PODER

Biblioteca ¿quéśs un nombro para onlo mundo? ¿una "Jorge Puccin ma solución pars todos sus enlgmas? ¿Una luz para tosotros foh desconocidos? joh quer. tes! toh Impávidos! job hombros de la me. dla nochel? Ealo nombre os la "Voluniad de domínio" y noda más (V. do P. 1067).

SUMARIO.- Vida y voluntad de poder. - Fllosolias del ser $y^{\prime}$ del devenir.El eterno reiorno $y$ la volunlad de poder. - La volunlad de verdad.- El mendaz "mundo verdad". -Fuerza y volumiad de poder- Pluralidad y multiplicidad de la voluniad de poder - La voluniad de poder en la "Wel. tanschaauung" nielzscheana.- Voluntad de poder, retorno o historia.

Si la vida es elerna el deseo de la vida no puede ser la fuerza cósmica primigenia, sólo a un iuberculoso como Spinoza se le pudo ocurrir aquello de "la conservación del propio Ser". Lo que la vida, la existencia quiere y es, es más vida, acrecentamiento de sí, dominio, voluntad de poder.

Este pensamiento lo encontramos en el mismo nombre ex sistere - el "ex" hace referencia a una relación que es ella misma lo primor- 
dial y sus aparentes términos apenas nada más que aparentes. Y lo primordial en ella es el poder, es una relación de poder, de fuerza. Pero guardémonos de las seducciones del lenguaje, de los que proviene da lógica, una simple semiótica. Relación no quiere decir relación enclos seres, entre dos objetos, dos algos, dos entidades. El lenguaje y la lógica no son apropiados para expresar la realidad del devenir. (Nietzsche coincide con los místicos en esta su desconfianza del lenguaje). Es simplemente una relación de poder $y$, mejor aún, un poder que se ;elaciona. No hay sin embargo, algo que pueda y una acción resultado de este algo. Hay solamente fuerzas o mejor aún, potencias que aciúan, en las que la separación entre un algo y su acción o acluación es una de esas peligrosas simplificaciones del lenguaje, simplificacioues contra las que Nietzsche nos previene llegándonos a decir que es un criterio de verdad el de que todo lo simple es falso. $\mathrm{Y}$ el monismo, tendencia innegable y aún primaria del pensamiento $-\mathrm{y}$, muy en particular, del pensamiento filosófico- es tambiến, por ello, igualmente peligroso. Quizás por esta razón la voluntad do poder en Nietzsche deviene inmediatamente en un pluralismo específico. "Astillad el todo", aconseja, y el mismo cumple el consejo. Pero, por otro lado, si por la tendencia monista puede fallar cualquier filosolía, sin ella es imposible cualquier filosofía. Esta contradicción es inevitable si tratamos de explicar la realidad, en esos idiomas que le son extranjeros: el lenguaje y la lógica.

Tratando de sítuar ta filosofia nietzscheana dentro de uno de los dos grandes polos de la oposicion parmenideo-heracliteana: Filosofía del Ser o Filosofía del devenir es lo corriente considerada como Filosofía del devenir. Sin embargo de su innegable mucha mayor cercanía e Heráclito - " El hombre tendrá siempre necesidad de profundidad y por ello tendrá necesidad de Heráclito" había escrito Nietzsche en alguna obra de juventud-- queremos destacar dos notas que caraclerizan de un modo rnuy peculiar la filosolía de la naturaleza del pensador:

En primer lugar la voluntad de Poder "es el hecho elemental", "no es un ser, no es un devenir. sino un "pathos", del cual resulta precisamente un devenir, un obrar". La Voluntad de Poder es una superación de la antinomia mencionada, aunque fuertemente inclinada de lado heraciliteano: La Realidad es el devenir, pero antes de él está la Voluntad de Poder. Evita, sin embargo, hacer de este conceplo una nueva entidad metafísica con su afirmación pluralista: no hay cosas, "sino cantidades dinámicas en una relación de tensión hacia otras can- 
tidades dinámicas cuyà esencia consiste en su relación con todas las demás cantidades, en ju obrar sobre éslas". (V. de P., 635).

Estas del Ser y del devenir no son para Nielzsche solamente dos fjlosolías diversas: tienen también una inmediata y máxima imporlancia moral "la hipótesis del Ser es la fuente de todas las calumnias contra el mundo (el "mundo mejor", el "mundo real", el "más allá", la "cosa en si').

En segundo lugar y, sin embargo de lo dicho anteriormente, la doctina del Eelerno Retorno de todas las cosas, representa el mayor acercamiento posible de una doctrina del devenir a una doctrina del ser: rada uno de los momentos del devenir es elerno, se repelirá infinilamen1e. El devenir ni ha comenzado nunca ni terminará jamás.

Si para una interpretación nihilista el eterno retorno es una nada eterna, para una interpretación superior, "más allá del nibilismo" aparece como la primera y más alta expresićn de la Voluntad de poder: "Todo retorno es el acercamiento exlremo de un mundo del devenir al mundo del Ser". "Imprimif al devenír el carácter del Ser es la más alla Voluntad de poder".

La voluntad de lo verdadera, no es sino el deseo de un mundo donde todo sea durable, por ello, expresión también de cierta voluntad de poder: La felicidad sólo está garantizada por lo que es; el cambio y lá felicidad se excluyen; para ser felices hay que lograr la ídentificación con el Ser. Bel mundo, fall como debiera ser, existe y el nuestro es el que es un error:g Unal descenllanzan $\forall n_{\text {tempr }}$ al devenir, una falta ce fé en él, de valor para vivirlo lleva a la creencia en el mundo del ser. Todo lo que responde a nuestros deseos, artificios e interpretaciones sicológicas, todo lo que veneramos y nos es agradable, se da ciia en ese mundo mendaz. El mundo real, en cambio, deviene falso precisamente por las cualidades que constituyen su realjdad: cambio, multiplicidad, contrastes, contradicciones. "Esle mundo" se identifjca con el "ma!"; se le considera mentiroso, engañador, desleal, falso, inesencial $y$, por consiguiente, no nos es útil (Hay que evitar asimilarse a el " vale más resistirle). El "mundo verdad", en tanto nos obliga a la creencia en él, es la que tenemos en los seres dignos de confianza. Por otro lato, nos impele cierto sentido de aventura: ese es el mundo desconocido, esto es, interesante, con lo que se insinúa que lo conocido es fastidioso.

Nietzsche usã irónicamente este nombre de "mundo verdad" que implica un conocimienlo de ese mundo. En todo caso tendríamos de- 
recho a hablar de un mundo que podría ser más inhumano, enojose e indigno.

Pero ¿porqué esa idea del otro mundo sólo ha sido empleada en desfavor, como crítica de esie mundo?. Esto es sintoma de confusión y debilitamiento fisiológicos y de equivocación sicológica en el filósofo que inventa un mundo al que la razón y las funciones lógicas le sean adecuadas, en el religioso que inventa un mundo divino, en è hombre moral que cree en el libre arbitrio $y$, por tanto, en este mundo bueno, perfecto, justo, sagrado. "Es el instinto del cansancio de vivir y no el de la vida el que ha creado el otro mundo". Es la voluntad de poder de la decadencia. "La filosofía, la religión y la moral sor. síntomas de decadencia" (V. de P., 586).

Desde el punto de vista mecánico lo que deviene es la misma can. tídad de fuerza. La consecuencia será que el devenir no tiene por ello ningún valor. Es el hombre, pero, sobre todo, por impaciente de su demasiado humana humanidad, cerca de lo sobre humano, el que pondrá un valor en lo que existe.

La voluntad de poder sólo puede manifestarse cuando encuentra una resistencia. La Física nos dice lo mismo del concepto de la fuer. za. La Sociología moderna 10 repite en el concepto de sinergia social. Para Nietzsche es el elemento decisivo de lo físíco, de lo físiológico, de lo sicolócico y de lo sociológico. Pero objeta el concepto de fuerza: "se le debe atribyir uniagyeluntad interionequeayo denomino "Voluntad de Poderío", o sea deseo insaciable de mostrar potencja o empleo. ejercicio del poder como instint creador, etc." (las utuerzas) se deben en. tender sólo como síntomas de cosas que suceden interiormente y servirse de la analogía del hombre con este fin". Es así que resuelve las fuerzas de "atracción" y "repulsión" de sentido puramente mecánico en manifestaciones de la voluntad de poder. "Nosotros no podemos pensar en un atraer que no tenga una intención. La voluntad de apode. rarse de una cosa o de defenderse de su poder y de rechazarla: esto es algo que comprendemos", es una interpretación de la que nos po demos valer. No malinterpretamos, sin embargo, el término "intención", este no debe ser escindido del poder actuante como lo haría cualquier teórico del conocimiento, nos agrega el fíósofo.

Esta Voluntad de Poder, primer principio de lo que existe, "naturaleza íntima del ser". (V. de P., 695). ¿Es una especie de voluntad o es idéntica con el concepto de voluntad?. ¿Significa lo mismo que aspira: - mandar?. ¿Es la voluntad de que Schopenhauer hace el "en sí" de las cosas? (V. de P., 692) se pregunta Nietzsche. 
No es una especie de voluntad, guardémonos de las sirenas de la lógica. Para la lógica formal sería un concepto específico subordinado del genérico "voluntad", pero para el filósofo es la realidad últimà de la cual deriva lo que existe - naturaleza y cultura-. Tampoco es la volurilad. La voluniad no existe (V. de P., 671, 715); es sólo "una concepción simplificadora del intelecto" (V. de P., 67l). No es tampoco aspirar aspirar o anhelar o desar. Todo esto se debe a la pasión del poder, (V. de P., 668). Tampoco es el "mando" porque puede expresarse precisamente en una resistencia, en una inconformidad con el mando.

¿Es la voluntad de la que Schopenhauer hace el "en sí" de las cosas?. "Los filósofos suelen hablar de la volunlad como si fuese la cosa mejor conocida del mundo: así, Schopenhauer nos enseña que la voluntad nos es conocida por sí misma y conocida completamente, sin íaltas ni sobras. Pero, me parece que también en este caso procedía Schopenhauer según el método de todos los filósolos, es decir, que se apropió de un prejuicio popular exagerándolo. El querer se me aparece como algo complicado, algo que sólo tiene unidad de palabra, en la cual tiene sus raíces el prejuicio popular del que se aprovecha la eterna imprevistón del los filósofos".

La voluntad - "esta cosa múltiple que el vulgo designa con una sola palabra" - nosólo es múltiple, es decir que comprende diversos elementos no volitivos, sensaciones y huchâ, pensamientos, afectos, rasgos de quien mandaccurandousecirafaldelohombreg sino también es plural, vale decir no hay una Voluntad como afirmaba Schopenhauer, sino numerosos "puntos "de Voluntad de poder.

Se ha censurado a Nietzsche el que hable de una Voluntad de Poder que permanece ignorada por las ciencias naturales (¿Es Nietzsche el Rousseau de la Revolución nacional socialista? Dr. A. Stern). "La doctrina de la voluntad de poder de Nietzsche es una metafísica natu. ralista". "Estimamos, sin embargo que dado que el naturalismo es una concepción exenta de valor, Nietzche no tenía derecho a considerar en este cuadro naturalista, la fuerza y el poder como valores superiores a la debilidad y a la impotencia. "Para las ciencias naturales puras no es el caballo más precioso que el tábano, la salud más preciosa que la enfermedad y la fuerza y el poder no están investidos de valores más elevados que la debilidad o la impotencia". "La naturaleza objetiva es indiferente respecto de toda diferencia de valor; no conoce ninguna jerarquía axiológica". Ahora bien ¿Qué entiende este señor por "naturaleza objetiva", naturaleza de las "ciencias naturales puras?": Es la 
naturaleza que nos proporciona la ciencia. Pero Nietzsche había com. batido a la ciencia de su época precisamente por esto. por lo que él llamaba "misarquismo" por el odio contra todo principio dirigente y ordenador, cuya aceptación hubiera podido ser la de la voluntad de poder. La ciencia para Nietzsche no tiene esa "objetividad" definitiva que para otros pensadores, por ello no es inconsecuente con su propio pensamiento. Si toda ciencia implica supuestos, una fé en sí misma que la mueva: si la objetjvidad no sólo no se alcanza nunca, sino que no existe - en buena cuenta es una convención del lenguaje (la pretendida de la ciencia es una como subjetividad pálida) - Nietzsche piensa que la ciencia debe aceptar como "a priori" - sólo que a priori real, sicológico y sociológico y no al modo de Kant - la dostrina de la Voluntad de Poder. La ciencia en cuanto instrumento de simplificación miente. "Todo lo que es simple es meramente imaginario, no es verdadero". La realidad es compleja e inasible en su complejidad por nuestra mente simplificadora, "ergo" falsificadora. Sin embargo como no tenemos otra para acometer esta tarea ineludible del hombre que es el filosofar, Nietzsche nos propone esa "clave" de la complejidad que es la Volun. tad de Poder. Entiende superar la mediocre pretendida "objetividad" de la ciencia con la visión genial - y por lo tanto visión no sólo de Nietzsche más engendrando otras semejantes, recordemos la etimología de genial - de la Voluntad de Poder.

La voluntad de poder es concepto fundamental, "clave" de la "Weltanschauung" nielzscheanal. Osire tenerla.en cuentą, fas distintas fórmulas nietzscheanas se nos aparecen incoherentes entres si:

Es la Voluntad de Poder la que determina el Retorno en el devenir puesto que ella quiere estabilidad. Ella es también la que determina la formación de todas las grandes funciones intelectuales. Es ella la que crea los valores, mediciones llevadas a cabo por los afectos humanos de los que es ella el primigenio. Es también la Voluntad de Poder la que nos sirve de modo de coordinación de las ideas al parecer antinómicas de Nietzsche: el retorno $y$ el Superhombre. Retorno que es una negación del progreso y Superhombre, que es en cierta forma una aceptación del mismo, aunque Nietzsche, como Schopenhauer, no cree en esta idea del oplimista siglo XIX. Puesto que no ha habido Superhombre en la Historia, pertenece al futuro y su realización es evidentemente "camino hacia adelante", "pro gressus" del grupo humano que encontrará en él y por él justificación. El retorno es una realidad cosmológica, el Superhombre será una realidad histórica. Los "tiempos" de estas dos ideas son opuestos y de allí la posibilidad de su conciliación. 
Billones de años, la unidad seguida de una gran cantidad de ceros y tiempo humano, años, siglos la segunda. La Voluntad de Poder del Unjverso es lo que produce el relorno, la Voluntad de Poder del hombre será la que al aumentar produzca el Superhombre. La Hisloria del Uni* verso es el círculo, pero se trata de una circuníerencia tan inmensa que la Historia de los agregados humanos, la Historia propiamente dicha, es prácticamente una línea recla irreversible. No debemos considerar el Retorno como una Filosolía de la Historia. Para Nietzsche la respuesla al problema de la Filosoía de la Historia es éstat La Historia tiene un sentido: el hombre superior, el grande hombre que le otorgan este sentido y que, por lo tanto, la justifican. El símbolo geométrico de la Filosofía de la Historia nitezscheana sería una línea en zjg-zag muy irregular. (El grande hombre puede producirse en cualquier pueblo, en cualquier época; hay pueblos enteros en los que abundan los hombres superiores) pero con los vértices más altos en el futuro (el Superhombre no ha existido jomás), el Superhombre que olorgará un sentido y será la justificación de la Historia toda.

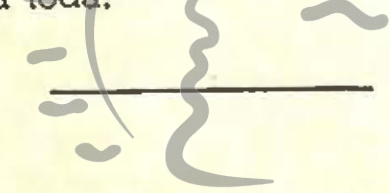

\section{Biblioteca de Letras}

"Jorge Puccinellic par mi el conocimlento os esto: Todo so que es profundo dobo elevarse "a mi altura"; (Zarathustra II. 12).

SUJMARIO.-- El Instinto da conocimiento.- La conciencia.- "Pensar".- Incortaprensibilidad del devenir.- Hechos $e$ interprelaciones.- El sujelo.- La ver. dad como expresión de la voluntad de poder.- La lógica $y$, sus categorias. - Los "errores irrefulables". - Consecuencias élicas de la falsa leoría del conocimiento.- El conocimietilo, leche de Precuslo.

En su esencia la nâturaleza es puntuaciones de Voluntad de Poder que lo aumentan o lo pierden. Sin embargo, por la necesidad de dominio tenemos que comprenderla como "cosmos", como "mundo", tenemos que calucularla y para calcularla tenemos que disponer de causas constantes. Como en la realidad no existen imaginamos átomos, causas, leyes, tines, necesidad. Pero esto no es comprender, como no sería cornprender una música calcular todo lo que en ella hay de calculable y reducible a fórmulas. Estas indican, describen, pero nada más. 
"El llamado instinto de conocimiento debe ser reducido a un ins. tinto de apropiación y de dominio: conforme a este instinto se han desarrollado los instintos, la memoria, los sentidos e incluso la conciencia: "Nuestro mundo interior también es fenómeno". (V. de P., 476). Todo lo que se hace consciente es tardío, final. El fragmento del mundo exterior del que somos conscientes, ha nacido después del efecto ejercido sobre nosotros por las cosas. La conciencia está quizá destinada a desaparecer y deiar lugar a un automatismo más perfecto, no existe; es una ticción completamente arbitraria realizada, separando del proceso ge. neral un sólo elemento, sustrayendo todos los demás elementos, un arreglo anticipado para entenderse" (V. de P., 477), para dominar. Y esto porque "un mundo en devenir no podría ser comprendido en el sentido estricto de la palabra; sólo en cuanto el intelecto que comprende y que conoce encuentra un mundo previamente creado por un procedjmiento grosero, construído de meras apariencias, sólo en cuanto este género de apariencias ha recibido la vida sólo en tanto, hay algo como un conocimiento, es decir, un medir los antíguos errores unos con otros" (V. de P., 250).

"No hay ni espíritu, ni razón, ni pensamiento, ni conciencia, ni alma, ni voluntad, ni verdad; estas son ficciones". No se trata de "sujeto y objeto", sino de una cierta especie animal que no prospera sino bajo el imperio de una justeza relativa de sus percepciones y ante todo con la regularidad de éstas. El conocimiento trabaja como instrumento de poderío; es precisolqueleutconcepcion de la fealidad abrace bastantes cosas calculables Y constantesn para Guevpueda nedificar sobre esta concepción un esquema de conducta". "La medida de la necesidad de conocer depende de la medida del crecimiento en la voluntad dé poderío de la especie: una especie se apodera de una cantidad de realidad para hacerse dueño de esta, para tomarla a su servicio. (V. de P., 480).

No hay pues "hechos" como quiere el positivismo sino sólo interpretaciones; no tiene el mundo un sentido fundamental, sino muchisimos sentidos. El mundo "ha llegado a ser para nosotros una segunda vez infinito: en cuanto no podemos refutar la posibilidad que contiene de interpretaciones hasta el infinito" (Gay Saber, 374).

Por otro lado, la realidad en que nosotros creemos y su gradación - mayor o menor realidad o apariencialidad — se deben a grados en el sentimiento de vida y poderío - lógíca y conexión en lo que ha si-
do vivido. 
"Sujeto" es una de las primeras ficciones del esquematismo humano de la realidad, para Nietzsche este concepto es anterior al de la sustancia y dice de él: "es la ficción que querría hacernos creør que muchos estados similares son en nosotros efecto del mismo substratum, pero somos nosolros los que hemos creado la analogía entre estos dilerentes estados". Y nuestro mismo pensamiento envuelve la fé en e! sujeto. En lugar de sujeto Nietzsche advierte una real pluralidad de sujetos. "Una especie de aristocracia de células en la cual esté el poder. algo así como "pares" que están acostumbrados a gobernar juntos y saben mandar".

"Todo el mecanismo del conocimiento es un aparato de abstracción y simplificación no encaminado a conocer sino a adquirir poder sobre las cosas". Lo necesario para la vida es que algo sea tenido por verdadero, no que algo sea verdadero. ¿Cuál es entonces la esencia de lo que se llama verdad?. Una valoración debida a la voluntad de aduenarse de la multiplicidad de las sensaciones: yo creo que esto y aque. llo es así.

La Lógica es resullado de una falsificación fundamental: No hay casos idénticos. Han sido los poderosos los que han puesto los nombres a las cosas y los más poderosos los que han creado las categorías. Y la verdod de eslas es su utilidad, es decir, el eslar al servicio de una Voluntad de Poder y el ser condiciones de subsislencia. La "razón" es apenas una idiosincragi de ciertas especies gnimales y sin embargo "el pensamiento racional es una interpretación conforme a un esquema del que nosotros nor podemos prescindir. "Culles son en último análisis las verdacies del hombre?.-- Sus errores irrefutables (Gay Saber, 265.).

En Nietzsche hay la impresión de un suicidio, de haber llegado a un límite, a un fin - y no importa la resurección dionisiaca - por estar viviendo eslas verdades que denuncian que lodas las consideradas así no son verdad en su acepción usual. Este aficionado a las alturas nos da la impresión de haber trepado por toda la estructura del pensamien. to racional y dominar desde la cima el panorama entero y descubrir que es el gigantesce "camouflage" de muy otra cosa que la voluntad de verdad. Esta teoría del conocimiento que Nietzsche denuncia y reprueba es reprochable y mala, no por ser falsificación, sino por sus consecuencias: Sobreestimación de la conciencia, identificación de la conciencia con Dios, el progreso debe ser un progreso de la conciencia; los sentidos y los instintos alejan de Dios. Y sobre todo, por esa máxima ficción que es el "mundo verdad". Mientras que el mundo de 
las apariencias es un mundo simplificado para nosotros por nuestros instintos prácticos $y$ por lo tanto verdadero para nosotros, el llamado "mundo verdad" es resultado de una audáz inversión realizada por ese gran artista de la decadencia griega, Platón; inversión aceptada por ei cristianismo y por la lilosofía posterior. En lugar de ver en la lógica y en las categorías de la razón medios para acomodar el mundo a fines utilitarios, se cree pozeer el criterio de la verdad, es decir de la realidad. Aunque se renegaba de Protágoras se caía en la ingenuidad de "tomar la idiosincracia antropocéntrica por medída de las cosas, como norma de lo "real" y de lo "irreal". Lo natural, lo sano era un útíl engaño para, por medio de él, dominar al mundo pero se introdujo una evaluación moral: "ninguna criatura quiere engañarse, ninguna criatura debe engañarse": por consiguiente, no hay más que una voluntad de lo verdadero. "Este es el más grande error que se haya cometido, la verdadera fatalidad del error sobre la tierra: en las formas de la razón se creía poseer un criterio de la realidad: mientras que no se mantenían esias formas sino para dominar a la realidad, para malentender la realidad de manera inteligente"

La Volunlad de Poder específica, humana, creó las categorías para una interpretación del mundo necesaria para su dominio y para la conservación de la especie. Estas dategorías que constituyen nuestro ineludible modo de conocimiento no obedecen a ninguna voluntad de verdad, no son ningún conocimiento con fines de verdad. "Hay sólo aprehensión de la redidad cont firrę deedonentio QSconservación. E! dominio de lo real resulla imposible sin estabilidad.sin duración. Todo el conocimiento - Nietzsche fo compara con el lecho de Procusto - un miedo de la voluntad a perder su poder, es la calalogación de lo nuevo en los moldes de lo antiguo. Del primer concepto, "Yo", nacen los demás: sustancia, causa, fin, necesidad, leyes, ser. Mientras que la realidad es voluntad de poder y se expresa en: cambio, diversidad, multiplicidad, el conocimiento es estabilidad, identidad, unidad. Por esto es que sólo podemos conocer la realidad - como Son Aqustín nos decía que podíamos conocer a Dios - por un "no saber" como trata de hacerlo Nietzsche.

Pero este instrumento cognoscitivo del hombre no se resignó a ser tal, desvaloró lo real, lo consideró inferior en jerarquía. El devenir apareció como falso y el gran instrumento calegorial como verdadero. Olvidó éste su significación real y aspiró a dar una concepción del mundo, del "mundo verdad". Esla oposición apariencia y mundo verdad 
se llenó de significado moral: El mundo aparente, el cambio, el devenir son malos, imperfectos, llenos de sufrimiento. El "Bien", y la "Perfección", la "Felicidad" son atributos del mundo verdad. Es pues el "mundo verdad" el que disminuye el valor del mundo que nosotros formamos y el que eleva dudas contra él; "el "mundo verdad" ha sido hasta el presente el más peligroso atentado contra la vida".

\section{III.- LAS PASIONES}

SUMARIO- Fiáón y pasión.- Valoración de las pasiones en las morales estoica, epicúrea. cristiana, kantiana.- Las pasiones en la moral nietzscheana.- Alqunas semejanzas entre Nietzsche $\gamma$ el sicoanálisis.-- Expresiones sicológica $\mathrm{y}$ sociológica de la Voluntad de Poder.- Superación de la oposición individualismo-colectivismo.- Las pasiones desde el punto de vista de la vida ascendente y de la vida decadente-- Virtudes y pasiones.- Las pasiones realizan y crean las marales.- Pasiones activas $\gamma$ reactivas.- La compasión y sus peligros.- Compasióm are ceceptaritu Nistasche.- La "virtud que dá". - La eritica de Scheler.

\section{"Jorge Puccinelli Converso»}

Sin embaryo del gran peligro significado por la hipóstasis del aparato conceptual, se ha establecido una jerarquía de "facultades" humanas" como si lo recto y lo normal fuése el dominio de la razón; mientras que las pasiones son consideradas como lo anormal, lo peligroso, lo semibestial y además por su fin, no más que concuspicencia. La pasión es degradada". Se ha desconocido la verdadera naturaleza de la pasión y de la razón "como si estas fuesen seres en sí y no lo que en realidad son, es. tados realtivos de diferentes pasiones y deseos y como si cada pasión no tuviera en sí su "quantum" de razón" (V. de P., 387). La revalorización de las pasiones, característica de la ética nietzscheana, ilumina bastante su concepto de la vida ascendente. Pero antes hagamos un breve recuento de la apreciación que han hecho de ellas las diferentes morales:

Los estoicos consideraron las pasiones - y en general los afectos y los sentimientos - como un aspecto patológico de la vida huma- 
na opuesto al natural, racional y coincidente con la Razón universal, cuya expresión era la naturaleza misma para estos abuelos del derecho natural. Por ello se debe buscar la libertad frente a las pasiones, no en su absoluta eliminación - y este es un prejuicio sobre los estojcos - sino en su máxima dabilitación. El prejuicio tendría, sin embargo, fundamento en el nombre " $\alpha-\pi \alpha v^{2} \varepsilon \iota \mid$ " que parece indicarnos carencia. Es porque las pasiones esclavizan, que el placer a que tienden debe ser evitado, es malo.

Los epicúreos habían subordinado el problema de las pasiones al del dolor o el placer que las acompañan. La prudencia es la virtud más alta, la que lleva al sabio a la dicha y le evita el sufrimiento. Pero los placeres no deben ser preferidos indistintamente - el epicureísmo considerado como un grosero sensualismo es un estúpido prejujcio - debe mos distinguir entre placeres naturales $y$ necesarios, naturales $y$ no necesarios y ni naturales ni necesarios. Asi mismo los del alma deben ser preferidos a los del cuerpo y los serenos a los violentos, siendo la "ataraxia" su expresión más completa.

El cristianismo, a través de su representativa la doctrina de Santo Tomás, ocupa una posición bastante cercana a la del estoicismo, sin su vigor. Las pasiones serian buenas o malas según su subordinación a no a la razón. Las mejores servidoras de la razón y las peores amas. Nietzsche, sin embargo, no sćlo no considera sino que no parece prestar la mayor atención Blalopinjón que sobre las tasiones pueda haber tenido el gran teórico del cristianismo.

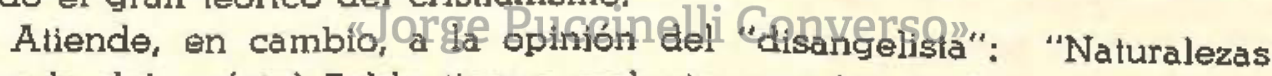
como la del apóstol Pablo tienen mal ojo para las pasiones; no saben distinguir en ellas lo que es malsano, lo que desfigura y rompe los corazones; su aspiración ideal sería pues, la destrucción completa de las pasiones, para ellos lo divino está completamente desprovisto de pasiones" (Gay Saber, 140).

Pero será, sobre todo, la consideración de las pasiones por las sociedades cristianas, la posición asumida por éstas ante ellas la que tome en cuenta y muy particular, naturalmente, la de la Iglesia: "¿Cómo era posible esperar de ella una guerra inteligente contra la pasión?. Ia Iglesia combate la pasión mediante mutilaciones en todo sentido; su práctica, su cura es el "castratismo". Ella no pregunta nunca: "Cómo se puede espiritualizar, embellecer, divinizar un deseo? En todo tiempo ha puosto su prurito en la extirpación de la sensualidad, de la flereza, de la avidez de dominio, de la sed de venganza. Pero atacar las pa- 
siones en su raíz significa atacar la vida en su raíz, la práctica de la Iglesia es hostil a la vida". (Crepúsculo V, l).

La moral kantiana es sabido que quita todo valor a las acciones llevadas a cabo por el empuje de alguna pasión, así sea de las consideradas como más nobles y altas: amor, honor, entusiasmo. La pasión, cuando no francamente mala, es por lo menos "adiáfora" desde el punto de vista moral. Este es otro de los puntos de más enconada oposición entre Nietzsche y Kant. El gran chino de Koenigsberg era repudiado por nuestro solitario como un anti-Goethe que separaba la sensualidad y el sentimiento de la razón y la voluntad allí donde Goethe quería, predicaba, era totalidad, la totalidad de la vida que es desear, amar, pensar, querer.

Para Nietzsche las pasiones son el verdadero sustratum de la naturaleza humana, la mayor intimidad de la sique del hombre $y$, por lo tanto, nos dan la clave de la vida ascendente o de la vida descendente. "La vida es el edificio fundamental de las emociones" (Más allá, 258). Allí donde una pasión tiranice a las otras, se haga tan fuerte que logre subordinarlas en una arquitecturación sicológica vigorosa y estable tendremos una vida de tipo ascendente. Esta tiranía no deberá ser, empero, debilitamiento de las pasiones dominadas, antes al contrario, el vigor de éstas es requisito indispensable para que la dominante sea aún más fuerte. Pero no sólo las demás pasiones son dominadas por ella: "Al más fuerte delnuestrosfinstintos, al tiranolinterior se sujeta no sólo nuestra razón, sing también nuestra conciencia", (Más allá, 158).

Es esta tensión de la lucha, cuya solución práctica es el poder, la realidad sicológica de la vida que asciende. Vale decir, de la vida moral mayor, de la moral-acción, de la moral sin moralina, de la moral inmoralista. Freud en algunos de sus libros afirma que el yo no es sino un complejo más fuerte que los otros. Complejo que no puede sino deberse a una o varias pasiones dominantes.

Aparece también la cercanía al sicoanálisis en el concepto de "libido"; tomado en un sentido sexual por S. Freud, Jung ha rescatado la acepción más amplia que tenía entre los clásicos latinos: "El término libido se emplea por cierto en la terminología médica para designar la volición sexual y en particular la concupiscencia. Sin embargo, los autores clásicos como Cicerón, Salustio, no conocen solamente esta definición unilateral; en la época clásica se ha empleado la palabra en ge. neral en el sentido de un deseo apasionado" (Jung-Teoría del Sicoanálisis II). 
La expresión personal, sicológica de la Voluntad de Poder no es, sin embargo, ni la única, ni quizá la más valiosa en el pensamiento de Nietzsche. La ética nitezscheana no es "individualista" en este sentido que pretende darle el Sr. Stern: "El esclavo es esclavo de sus propios instintos, de sus propias angustias, de sus propias debilidades. He aquí la fórmula más clara que se puede eztraer de manera esotérica de la distinción nietzscheana de amos y esclavos". No tanto de manera esotérica cuanto de manera arbitraria, de la manera más arbitraria.

No acepta Nietzsche el "yo" que puede o no mandar en la interioridad. "La voluntad de dominar una pasión no es al fin y al cabo sino la voluntad de otra u otras pasiones" (Más allá, 117). El yo no representa casi nunca nada, o muy poco: hombres de instintos y pasiones débiles $\mathrm{Y}$ anárquicos o es una realidad: hombres en los que una pasión - complejo diría el sicoanálisis - organiza a los ołros. Pero esta es una primera tarea después vendrá la relación de dominio con los demás hombres, relación muy espiritualizada en Nietzsche, que no implicará como implicó en el pasado algo parecido a explotación. Los dcminadores serán más sobrios y más pobres. $Y$ aún no es indispensable para la validez de su tipo que electivamente ejerzan el dominic porque a veces huyen de las plazas públicas. Podrán dominar la dominador o dominar el sentido de la vida, al crearlo, creando nuevas tablas de valores que van a obedecer los demás. La filosofía es la más espiritual voluntad de dôminio (Más allá, do).

No hay en Nielzsche el individualismo robinsontano, ese que se ha

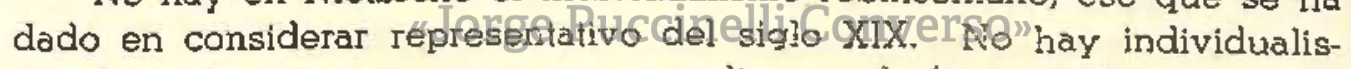
mo de tantas otras maneras que repudiamos el término, Nietzsche pretende y sabe esto mismo. "Ponerse fuera de estos dos movimientos, de la moral individualista y de la colectivista, porque tampoco la primera conoce la jerarquía y quiere dar a lodos la misma libertad. Mis pensamientos no giran alrededor del grūdo de libertad que se debe conceder al uno o al otro $\circ$ a todos, sino sobre el gracio de poder que uno u otro deben ejercer sobre otros o sobre todos; o sea, sobre la medida en que un sacrificio de libertad y hasta un hacerse esclavo ofrecen la base a la producción de un tipo superior. En la forma más tos. ca ¿Cómo se podría sacrifícar la evolución de la humanidad para contribuír a la existencia de una especie más alta del hombre"'” (V. de P. 859).

La relación sicológica es, pues, sólo un primer momento; el segundo será lo intersicológico, lo social: una arqujtectura frente a muchas otras. 
Las pasiones cébiles, al mismo tiempo anárquicas, pálidas, pero sin la palidez de la ambición de mando sobre las olras nos suministran la fórmula de la vida decadente:

"La multiplicídad y la disgregación de los insluntos, la ausencía de un sistema que los regule, uniéndolos y ordenándolos lermina en la "debilitación de la voluntad"; la coordinación de estos instintos bajo la dominación de uno sólo termina en la voluntad fuerte". La primera expresión en el hombre de la voluntad de poder es el efectivo pode: de un instinto, de una pasión sobre otras en la organización concreta de la sique humana. No se logra por debilidad o anarquía de instintos:

En un individuo se debe distinguir:

1) La pasión dominante que en general lleva consigo también la forma suprema de la salud; aquí es mejor conseguida la coordinación de los sistemas internos y su colaboración en un sólo servicio, pero esta es casi la definición de la salud.

2) El contraste de las pasiones, la existencia de dos, muchas "almas en un sólo pecho": cosa bastante malsana, ruina interior, cosa disolvente que Iraiciona y aumenta un divorcio interior, una anarquía interior, a menos que una sola pasión sea la que domine: retorno de la salud.

3) La coexistencia de sus pasiones, sin que estas se contrasten o se favorezcan entre síy con frecuencia es periódica y entonces, una vez restablecido el orden, es también sanada. A esta especie de pasiona. les pertenecen los homabrescmás interesantes:sdos camaleones...." (V. de P., 778), camaleones que no ascienden sino que cambian.

Más, ¿Qué vendrian a ser en última instancia las virtucles?. Lo que hay trás de cada virtud es una pasjón, nos dice Nietzsche.

"Todas las virtudes, estados fisiológicos: sobre todo, las principales funciones orgánicas como necesarias, como bien sentidas. Todas las virtudes son realmente pasiones refinadas y estados de exaltación".

La compasión y el amor a la humanidad como evolución del instinto genésico. La justicia corno evolución de la venganza. La virtud como juego de resistencia de voluntad de poderío. El honor como reconocimiento de lo semejante y de lo equivalente" (V. de P., 255). "Ca. si todo lo que llamamos "cultura" se basa, en la espiritualización de la crueldad". (Más allá, 229).

Pero las pasiones son lodavía decisivas en la moral de otra mane. ra para nuestro mostachudo solitario, que sostiene que no hay fenómenos morales، sino interpretación moral de los mismos. (Más allá IV, 108). "Interpretación llevada a cabo por los afectos". V. de P., 254 in 
fine). "La moral no es olro cosa que el lenguaje figurado de los afectos". (Más allá, 187). La crítica a los sistemas de moral hecha por el filósofo que afirma que su genjo está en sus narices, consiste, pues, en buscar las pasiones - correlato siempre de estados fisiológicos y susceptibles de devenir "virtudes" al espiritualizarse - de las que son expresión. Pero las pasiones no sólo constituyen o nó la afectiva realización de una moral, sino que crean los mismos sistemas de moral que según el terreno fisiológico y pasional que les sirva de sustento recibirán o no la aprobación de este solitario que filosofa con el olfato.

No todas las pasiones merecen el sí de Federico Nietzsche. Las que significan afirmación gozosa, triunfal, exultante de la vida y de la voluntad de poder, de la exhuberancia, de la riqueza, de la abundancia personales son las preferidas: "el orgullo, la alegría, la salud, el amor sexual, la enemistad y la guerra, el respeto, los bellos gestos, las bellas maneras, la fírme voluntad, la disciplina de la alta intelectualjdad, la voluntad de poderío, el reconocimiento que es rico y quiere ceder y hacer donativos a la vida y la dora y eterniza y la diviniza, todo el poderío de las virtudes transfigurativas, todo lo que aprueba, afirma. obra afirmando" (V. de P., 1033).

Son las pasiones acción. A su lado tenemos las pasiones reacción que no expresan como las anteriores una vida rica, fuerte, gozosa, por imposibilidad fisiológica de estas características. Son las pasiones que crecen en una fisiologíacébic miseablecquêno puede expandirse, verterse; que tiende grenas a conservarse Ýs defenderse de las pasiones acción: Ojeriza, enemistad, odio, envidia, precisamente de qulenes poseen - son - las anteriores. El resentimiento, "le ressentiment" simbolizaría las pasiones reacción. En él, en ellas, se conserva y defiende la vida empequeñecida, empobrecida contra la vida ascendente. Es una defensa inspirada por el temor. Temor a la vida que contrasta con la gratitud de la vida que desbordan las pasiones ac. ción. Estas crean morales de señores. Las pasiones reacción pueden también devenir geniales y crear morales, pero serán morales de esclavos en las que la mendacidad fisiolćgica, los instintos empobrecidos, las pasiones reactivas estarán presentes; no sólo defendiendo y conservando a los miseralbes sino cautivando a los fuertes. a los señores, haciéndolos caer bajo sus sortilegios. Bajo los hechizos de que sabe siempre rodearse la debilidad y a los que los señores no resisten, y a menudo sucumben por su ingenuidad, por su amor al peligro, por su generosidad. 
Y por su compasión. Así como el dolor aísla y nos lleva por el camino de la soledad hacia ese ser nosotros mismos que constituye cumplimiento de la moral del inmoralista Nietzsche, así este vivir el dolor de otro, sumar al suyo nuestro dolor comienza por ser un sacrilicio de ese "pathos de la distancia" insustituíble virtud del tipo moral superior del filósofo.

Pero lo suprime tanto en quien compadece como en el compade. cido; el sufrimiento de éste tieno efectivamente algo de personal, de incomprensible e inabordable en su mayor intimidad. "E'n la mayor parte de los beneficios que se prodigan a los desgraciados, hay algo de repugnante a causa del descuido intelectual que el compasivo pone el jugar al destino: no sabe nada de las consecuencias $y$ de todas las complicaciones interiores que para mi o bien para tí se ilaman desgracia". (Gay Saber, 338). "De aqui que todo hombre noble se impon. ga el no humillar a los demás; se impone el pudor do todo lo que sufre".

"Ciertamente no me agradan los misericordiosos que buscan la bea. titud en su piedad; están demasiado desprovistos de pudor" (Zarathustra, II, 3).

Para el compasivo la compasión es una seducción que le aleja de su propio camino, a la que debe saber resistir. Pero "la opinión de los predicadores de lajiriol c de la piledad Hega en nuestros dias a pretender que ésto $Y$ ésto solamente es la moral; a saber: desviarse de su camino para aculirgen $\mathrm{P}$ sberro del poolifo. $80 "$ "

Por otro lado, para Nietzsche la compasión dificulta la selección, conserva lo que está a punto de de perecer, obra tamblén en calidad de "conservador de los miserables" (Anticristo, 7).

La compasión produce en el compasivo "un efecto depresivo", con ella aumenta y se multiplica la pérdida de fuerzas que el sufrimiento aporta ya a la vida; "está en contradicción con las emociones tónicas que elevan la energía del sentimiento vital". "Nada es más malsano en nuestra malsana modernidad que la compasión cristiana". "Con la compasión la vida es negada y se hace más digna de ser negada; la compasión es la práctica del nihilismo", "nos encariña con la nada" (Anticristo, 7).

"Aristóteles vió, como es sabido, en la compasión un estado de ánimo morboso y peligroso que sería bueno tratar de cuando en cuando con un purgante; consideró la tragedia como un purgante". El pensador se refiere a la célebre teoría del Estagirita sobre la catharsis, 
es decir el sentido liberador de lo malsano que para él tenja la tragedia.

No la compasión, es decir, la conmiseración, sino la com-pasión, la sim-patía entre iguales "inter pares": "a tus amigos y solamente de la manera como tú mismo te prestas ayuda a tí mismo". Y mejor que todo "no la pena en común sino la alegría en común" (Gay Saber, 333).

Habría otro modo de compasión - la del propio Nietzsche - no por la miseria social y por la sociedad, no por los males del cuerpo, sino la provocada por el empequeñecimiento del hombre. "Hay un contraste entre vuestra compasión por lo más bajo del hombre, por lo que debe perecer - nos dice Nietzsche - y nuestra compasión por lo más sublime, por lo que debe vivir".

No niega lampoco el filósofo la conmiseración en todos los casos. La señala como valiosa cuando existe una gran riqueza de personalidad; "Un hombre que nació amo y se tompadece, esta compasión es valor. ¿Pero qué vale la compasión de los que deben ser compadeci. dos, ni la de aquellos que predican la compasión? Hoy en Europa encontramos una sensiblería morbosa para el dolor $y^{\prime}$ al mismo tiempo una intemperancia en el lamentarse, una afeminación que se dá aires de superioridad bajo la máscara de religión $Y$ de orgullo filosćfico: se ha decretado un verdadero culto del sufrimiento" (Más allá. 293). "Desgraciados de los que aman sinOtener una Elevación que esté por encima de su piedad". (ZarathustraP Irçnelli Converso"

De muchos modos es pues nociva la compasión para nuestro filósofo que le opone una cualidad que guarda cierta semejanza con ella y que es de las altas y elevadas, símbolo de todas las virtudes: "la virtud que dá"; contra el egoísmo del alma raquítica que quiere todo para si". "la virtud que dá" es la ofrenda que de sí misma hace la vida rica a los demás. Pero es necesario para poseerla que "el corazón desborde todo él - parecido a un caudaloso río - bendíción y peligro para los ribereños" (Zarathustra J. 23).

La concepción nietzscheana de la compasión ha sido crilicada como es sabido por Max Scheler, quien advierte que Nietzsche no ha distinguido entre el contagio afectivo ("Gefuhlsansteckung") de la simpatía propiamente dicha ("Mitgefuhl"). Este error - herencia de Schopen. hauer que valoraba positivamente una "compasión" que comprendía ambos sentimientos - ha llevado a Nietzsche a desvalorarlos, olvidando su diferencia y aún su oposición, - pues para Scheler la auténtica simpatía, compasiva o nó, hace desaparecer el contagio sentimental: 
"Multiplicador de la miseria sería la compasión tan sólo si fuera idéntica al contagio afective" (Scheler - Esencia y formas de la simpatía, A, II). "Un valor negativo, como simple aumento del padecer, representa el contagio" (Ob. cit., A, XI). Scheler rechaza la ética de la simpatía, pero admite el valor ético de la simpatía, no por si misma, sino porque: "Todo simpatizar está fundado en un amor y sin un amor cesa" (Ob. cit. A, XII). Y el amor es el constante portador de valores.

\section{IV.- LA IERARQUIA}

SUMARIO.- Ierarquia y poder.- jerarquía y soledad- jerarquía, e idoalismo- - La jerarquia. las acciones, la fí.- Psnsamiento orulto de Nielzsche. - Pueblos pronisores.- Sentido de la prédica de alchunas extremas medicins de eugenesia.

\section{Biblioteca de Letras}

Un hombre o una sociedad de vida ascendente se diferencian de un hombre o una sociedad de vida decadente" en cuanto representan un logro mayor de jerarquía. ¿Qué es lo que determina la jerarquía? -- Unicamente las cualidades de poder y nada más. (V. de P., 855). La jerarquía es el ordenamiento del poder (V. de P., 856). Pero con la doctrina de la igualdad, nos dice Nietzsche, todos tienen derecho a cualquier problema, es decir, se ha perdido toda jerarquía. Para restable cerla sería necesaria una "guerra de los hombres superiores a la masa". (V. de P., 861).

Nos indica la jerarquía el "hasta qué punto un hombre es solitario - tiene instintos de rebaño. (En el último caso su valor consiste en las cualidades que aseguran la existencia de su rebaño, de su tipo; en el primer caso en lo que le enaltece, le aísla, le defiende y hace posible que sea solitario)". "No se debe valorar el tipo solitario según el rebaño, ni el del rebaño según el solitario". mirados desde arriba ambos son necesarios" (V. de P., 114).

Nietzsche encuentra despreciable el idealismo que quiere que el mediocre, el perezoso, el vil, el mezquino dejen de serlo. En un filóso- 
fo este odio es aún más indigno, porque es la excepción y debe tomar la regla bajo su protección. La guerra de que habla el mismo Nietszche no es para que la masa abandone las cualidades que la caracterizan. sino que es contra la masa misma para limitar su campo y disminuir su influencia.

¿Es en las acciones donde se muestra la jerarquía? Nietzsche pensaba que es una inconveniencia y una equivocación para la aprehensión de un hombre el basarse en sus acciones - como lo hace Buckle "un vulgar agitador de multitudes" - y menos todavía en una sola acción como lo hace el derecho penal: "No las obras sino la fé determina la jerarquía" (Más allá del Bien y del Mal, 287). El aristócrata tiene fé en sí mismo, se venera a sí mismo, en esto y no en alguna o muchas obras está su superioridad. "Las acciones están siempre sujetas a múltiples interpretaciones". Este fué el error de la valoración moral: considerar al hombre "sólo en relación con los hombres" (V. de P., 878).

Para comprender la afirmación de Nietzsche sobre la necesidad de dos morales debemos tener en cuenta su pensamiento oculto sobre la utilidad y la justificación de la "decadencia", sobre cómo es que la decadencia, le degeneración y todos los instintos empobrecidos y des. viados, hacen posible una afirmación más intensa de la vida, ya que entonces, sólo entonces, Jôs límites del sentimiento vital se hacen mayores y por lo tanto las contradicciones de la vida- que son la vida misma - más intensas. r.ge Puccinelli Converso"

¿En comparación con los animales hay en el hombre mayor o menor realización de los valores vitales de la Voluntad de Poder esencia de la vida?. Así como Nietzsche, antes de su último colapso, hablaba de su enfermedad "a la que debía una salud mejor" así como en el hombre Nietzsche debido a una enfermedad aparecía un valor vital mejor", así en el "hombre", animal debilitado en comparación con los demás, cabe una vida mayor, una superior afirmación de la vida, una expresión más lograda de la Voluntad de Poder. Para su manifestación más alta es sabido que Nietzsche ha encontrado la "fórmula" Superhombre.

Y así como en el hombre Nietzsche y como en el hombre en general, así también en la sociedad. Sólo allí donde haya una masa de seres humanos "religiosa", "demócrática"", "socialista", es decir "decadente" podrá afirmarse el opuesto de la decadencia, el Superhombre. Entre ambos "se debe cavar más profundamente el abismo" (V. de P., 891). 
La historia después de los milenios recorridos nos ofrece mayor posibilidad de contrastes sociales y de contrastes síquicos. Al lado de una nivelación llevada al máximo, de una "administración económica de la tierra", que Nietzsche anunciaba y en la que cada hombre sería nada más que una función, la posibilidad paradojal abierta por este mismo hecho de un hombre superior que dominara a los demás. La enorme diferencia social hará posible en el alma de los señores los necesarios grandes contrastes. Sin el "pathos de la distancia" "no sería posible el otro misterioso pathos, el deseo de ampliar las distancias dentro del alma misma, el desarrollo de esiados anímicos cada vez más elevados, más variados y lejanos, en una palabra la elevación del tipo hombre" (Más allá del Bien y del Mal, 257). El gran sociólogo Gabriel Tarde también dirá que la diferencia "es el alfa y omega del Universo".

La historia nos ha ofrecido pueblos, clases e individuos aislados que, de un modo u otro, representaban la vida ascendente, pero Nietzsche piensa que lo ha sido producido de un modo eventual, inconsciente, casual, puede ser querido y provocado conscientemente.

En todo el abigarramiento y la confusión que caracterizan la modernidad repudiada por Nietzsche, este no deja de ver algunos signos alentadores: "La destreza viril personal, la aptitud del cuerpo, recuperan otra vez su valor, las valoraciones van siendo más físicas, la alimentación más carnívora. Otra vez van a ser posible los hombres bellos" (V. de P., 127). "Se ha vuelfo a la naturaleza pero no a la naturaleza razonable, inocente y bella, buena de Rousseau. Se la sabe indiferente a la virtud, pero por esto mismo se la estima. Se antepone la salud del cuerpo a la del alrna, que aparece como consecuencia. Se tiene una "actitud más inofensiva para con los sentidos, una actitud más benévola, más regocijada, más a lo Goethe para con la sensibilidad" (V. de P., 118). L.os hombres del siglo se hacen cada vez más decididamente antiidealistas, objetivos, impávidos, trabajadores, mesurados". Con esto ha conseguido superar el siglo XVIII y abrir la vía por la que marcha nuestro siglo XX.

Los pueblos con una cierta ingenuidad en la expresión de la voluntad de poder, le parecen los más promisores: "En el Teages de Platón se lee: "Cada una de nosotros querría ser señor de todos los homhres y mejor que esto, Dios". Esta mentalidad debe volver a producirse.

"Ingleses, americanos, rusos" (V. de P., 958). 
Nietzsche quiere una moral que permita educar a una especie de hombres que sea capaz de administrar la tierra como un todo, pues cree pasada la época en que el bien y el mal de cada pueblo era diferente del de su vecino. Uno de los muchos motivos de su estima por Napolećn es que quería dominar Europa para que Europa dominara al mundo.

No se debe interpretar como quería Comte - ese "astuto jesuíta" que quería "conducir a los franceses a Roma por la Vía de la Ciencia" - como un deber de la especie superior el dirigir a la especie inferior, la que es sólo base vital de la primera que vive para cumplir sus propios deberes: no es medio de conservación del rebaño, sino fin y sentido de la existencia del rebaño.

"La defección, la descomposición, el perecimiento no tiene nada de censurables en sí mismos; no son más que consecuencia necesaria de la vida, del crecimiento vital. El fenómeno de la decadencia es tan necesario como el del florecimiento y progreso de la vida; pero no poseemos el medio de suprimir este fenómeno". (V. de P., 40).

"La decadencia misma no es que se tenga que combatir, es absolutamente necesaria y propia de toda época, de todo pueblo. Lo que hay que combatir con todas nuestras fuerzas es la importación del contagio a las partes sanas del organismo" (V. de P., 40). "El empequeñecimiento del hombre debe ser considerado por largo tiempo com el único fin, porque hay que crear primero una amplia base para que sobre ella pueda sustentarse una especie de hombres más fuerte" (V. de P., 895).

El peligro no es, pues, la existencia de la decadencia, el peligro está en su victoria sobre lo que no es decadencia, sobre la fuerza, sobre la vida. Cuando la decadencia es un escalón y mejor un pedestal de la vida fuerte, ascendente, ésta es aún más fuerte y se logra más completamente, pero la decadencia puede inficionar, contagiar, enfermar a los fuertes; esto es lo que Nietzsche trata de evitar: ¡Que un Pascal se haga cristiano!

Unamuno elogia la definición de la vida del biólogo Bichat: la no muerte. Y de esta lucha contra la muerte viene su hermosa concep-

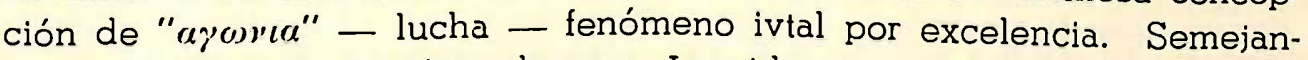
te es el pensamiento nietzscheano. La vida es ya no lucha, sino poder sobre algo, es poder de lo sano, sobre lo degenerado y enfermo que no debe perecer sino estar subordinado.

Importa aclarar que nuestro filósofo no entiende por "privilegiados" nada parecido a privilegiados de clase explotadores de una clase 
inferior que viva en la pobreza mientras ellos se encuentran en la abundancia. Una explotación análoga a la que señala ei marxismo. No. No se refiere a los privilegiados de la riqueza:

- Los obreros vivirán un día como ahora viven los burgueses, pero sobre ellos y distinguiéndose por su falta de necesidades, las clases superiores: por lo tanto, vivirán más pobres y más sencillamente, pero en la posesión' del poder" (V. de P., 764).

Debemos señalar también el carácter de inconsecuencia para con el propio pensamiento que en el fondo tiene el predicar la eutanasia, la esterilización y aún la castración de criminales, degenerados, enfermos, etc. Ha sido tomada al pié da la letra cuando, a nuestro parecer, representa una exageración polémica de Nietzsche que, en todo caso, vale como algo que se debería estar dispuesto a hacer si fuera indispensable a la vida superior, pero que resulta precisamente inconveniente para ella que encuentra en el abismo de la distancia con respecto de otros hombre el mayor impulso para lograr en las almas individuales el abismo entre unas y otras pasiones indispensables a esa máxima tensión de poder que es expresión suprerna de la vida.

Para la filosofía de Nietzsche no hay "la verdad", sino "mi verdad". tantas verdades como perspectivas, y el modo de hacerlas influir sobre los demás es no sólo desfigurar y caricaturar el adversario ,sino también exagerar algunos' de los propios rasgos, para adquirir mayor vigor. Eutanasia, estifilizacióne $q$ castraciónede enfermos y degenerados, son si no de estas exageraciones, rasgos inesenciales del pensamiento nietzscheano.

\section{V.- FIGURAS DE LA VIDĀ ASCENDENTE}

"En lugar de sociología, una doctrina de los modelos de señorío" (V. de P. 462).

SUMARIO.- Dificultad pata precisarlas 1) La persona-Pocos hombres son personas-Características de la persona.-2) Los bárbaros del porvenir-Superioridad intelectual y fuerza.- 3) El hombre fuerte-Importancia de la herencia-Sus señules-Características y medio de educación y conservación. -- 4) El hombre noble-La "observación para los asnos"-Cualidades del aristócrata-Vanidad y egoísmo. dolor, unicidad-Peligros que acechan al hombre noble.- 5) El grande hombre-Cualidades de la grandeza-El gran estilo-El grande y el fanático.- 6) El hombre superior-La trasmutación de valores. - Caracteres del hombre superior.- La gran politica educacional. -La preparación del porvenir. 
Nietzsche no sólo nos señala características de la vida ascendente sino que procede a una tipificación más detallada de la misma, aunque no tenga una mayor precisión (lo que parece debərse a no haber concluído su "Voluntad de Poder", en la que realiza este intento). Entre los estudiosos de Nieizsche, Piänder sólo considera junto al Superhombre al "distinguido"; Ch. Andler habla del "noble" el "grande hombre" y el "hombre superior". Nosotros arriesgando el pecar de excesivamente minuciosos, inspirándonos más literalmente en el mismo Nietzsche, señalamos "la persona", el "bárbaro del porvenir", el "hombre fuerte. el "noble", el "grande hombre" y el "hombre superior". A veces los tipos están apenas esbozados $y$, en algunos casos, parece tratarse de dos grados de un mismo tipo, pero debemos tener en cuenta que un mayor desarrollo de la vida ascendente determina mayores cualidades y que para Nietzsche las diferencias de cantidad expresan las cualitativas.

"La persona" ligeramente esbozada, representa una figura solitaria que se dá en las sociedades democráticas, nos parece que su ulterior evolución es "el hombre superior". "El bárbaro del porvenir" representa un grupo de hombres - no señalamos la coincidencia con bárbaros ya del pasado para no parecer demasiado actuales en la exposición de un filósofo que nos recomendaba tan severamente la inactualidad y el amor a lo lejano. El "hombre fuerte", más solitario, en. cuentra su figura superior en "el grande hombre". El aristócrata repre. senta una espiritualización del bárbaro proto-histórico, aunque no es el aristócrata decadente" der algunas cortes leuropeas. SOEl "hombre superior", educador del tipo más elevado, vive para ese porvenir que es el Superhombre, el que vivirá en su presente el cumplimiento de la vida; el "hombre superior" es una figura de inteligencia enorme que no queremos llamar intelectualizada para no rebajarla.

Conviene quizá la acalaración de que, como en toda tipología sicológica, los hombres reáles a menudo exceden uno o varios tipos y a veces, en rigor, no deben ser colocados en ninguno de ellos. Estas "figuras" constituyen, sin embargo, modelos para la clasificación de la vida ascendente, de la grandeza humana, en la que la vida se logra y la historia se justifica.

Nada más lejano de "la persona" que el concepto que Maritain tan el de nuestra filosofía contemporánea - tiene de ella: "No se debe suponer que muchos hombres sean personas" comienza por decir nos Nietzsche (V. de P., 886). Ya en el Zarathustra nos había dicho que "los hombres en nada son iguales". La persona es "un despilfarro, 
un lujo", "un hecho relativemente aislado, en relación con la mucha mayor importancia de lo continuo y de io mediano es casi contra-natural". Ningún biologismo, ningún darwinismo en la afirmación. El vitalismo de Nietzsche supera muy pronto su poco afortunada y felizmente pasajera etapa biológica. Los caracteres que hacen una "persona" serían "recisivos" y no "dominantes" para la terminología mendeliana.

¿Qué determina la formación de la persona?. La soledad, el amurallamiento, la segregación de un determinado ambiente. (V. de P., 886).

¿Dónde se encuentran làs personas?. Prosperan las más veces en los elementos más bajos y más sacrificados; si se buscan personas se encuentran allí más seguramente que en las clases medias.

"En cierto sentido, éstas se puede más fácilmente conservar y desarrollar en una sociedad democrática; cuando los meciios de defensa más groseros no son ya necesarios y un cierto hábito de orden. de elocuencia, de justicia, de confianza forma parte de las condiciones ambientes" (V. de P., 887).

Los bárbaros del porvenir unirán la superioridad intelectual con el bienestar y con el exceso de fuerza; amarán, por encima de todo, la simplificación del gusto clásico. Vivirán el dilemà: perecer o imponerse. Será una invasión vertical de bárbaros de la misma dirección, pero de sentido opuesto a la que menciona W. Rathenau. La de Nietzsche será una invasión dé bárbaros de lo alto, venidos del espíritu, con él. Se habrán podido desarrollar "merced a principios terribles y vlolentos" "se harán visibles yose cofsolidarán solamente" después de enormes crisis socialistas, serán los elementos capaces de la mayor dureza para consigo mismos" (V. de P., 868). Los artistas y los hombres de Estado, "barbarie domesticada" entre los que tienen cierta expresión estas grandes pasiones sistemáticamente persıguidas, podrán darnos una pequeña idea de como serán.

Todas las figuras de la vida ascendente tendrán algo de bárbaro, de terrible, en comparación con el "civilizado" - hombre debilitado, empequeñecido - contemporáneo de Nietzsche.

Hombre fuerte y hombre débii es otro de los modos de enunciar la polarización de los humanos. No hay ni mérito ni culpa en ello. En lo fundamental son debidios a la herencia: "El concepto de hombre fuerte y hombre débil se reduce a esto: que en el primer caso se ha heredado mucha fuerza, este hombre es una suma; en el segundo caso se ha heredado menos fuerza" (V. de P., 863). 
El hombre fuerte se señala porque puede digerir sus actos como digiere sus alimentos, pero "en las cosas esenciales le guía un instinto innato y severo que le impide hacer lo que le perjudica como que no le place" (V. de P., 906). ¿Cómo se llega a ser más fuerte?. "Decidiéndose lentamente $y$ ateniéndose tenazmente a lo decidido. Todo lo demás se nos dará por añadidura" (V. de P., 918). No se debe frecuentar a los benévolos, su liato debilita, por el contrario: "Sólo en condiciones terriblemenie ciestavorables adquiere nacimiento, fuerza y vigor una especie o un tipo".

Nietzsche señala la importancia casi insustituíble de una educación conveniente; "Yo no comprendo como un hombre que descuide ir a su tiempo a una buena escuela puede hacer nada bien" (V. de P., 921). La "misericordiosa vida" puede en ocasiones hacernos recuperar esta experiencia más tarde, mediante todo género de males: "A los hombres, por quienes yo me intereso les deseo sufrimientos, abandono, enfermedad, malos tratos, desprecio; yo deseo que no les sea desconocido el profundo desprecio de sí mismos, el martirio de la desconfianza de sí mismos, la miseria del vencido; no tengo compasión de ellos" (V. de P., 910).

Nos señala el filósofo los medios de conservación de esta especie más fuerte:

La lucha; la paz sólo resulta posible "a la sombra de las espadas". El derecho a las acciones excepcionales e a estados de ánimo en que tengamos que ser bárbaros. El ascetismo que debe ser naturalizado, ya no el camino hacia la nada def sacerdote, que prefiere "la voluntad de la nada a la nada de la voluntad", sino un instrumento de robustecimiento de la voluintad. "Los educadores imponen exámenes para todo, pero no para lo principal: si se sabe querer, si se está en estado de prometer". El ayuno "en todos sentidos": de lecturas, de música, de amabilidad, "debe haber días de ayuno aún para la propia virtud". No comunicarse, callar. La claustración, sin correspondencia epistolar, "un salir de la danza de circo del "milieu", permite la acumulación de la fuerza. (Nietzsche mismo había propuesto a sus amigos este convento laico del cual participó más tarde él, en la villa "Rubinacci" de la Sra. Von Meysemburg, en Sorrento). La obediencia y la casuística extrema en el punto de honor. El "no hagas a otro lo que no quieres que te hagan a tí de John Stuart Mill tiene como pensamiento recóndito el de que toda acción puede ser recompensada, "la premisa es innoble en el más bajo estilo" y es contraria a las acciones dictadas por el sentimiento del honor en que somos indiferentes a las consecuencias, 
nos dice el filósofo. La consideración de que se distingue al tomar represalias.

Son los fuertes los que hacen la historia, no la masa de los débiles que no es en realidad una suma. Si son los valores de los débiles los más prestigiados, se debe también entre otras cosas a que los fuertes dominan sólo a través de ellos. Pero estos valores son a veces instrumento del dominio de los propios débiles, más interesantes, más fascinadores, más malignos, más múltiples: (semitas, franceses, chinos, señala Nietzsche). No se crea que este es un riesgo antibiológico; es todo lo contrario. Precisamente el triunfo de la gran masa de los débiles, de los mediocres y de sus valores es lo biológico, resultado de una vida que quiere conservar una especie, conservando la gran masa de los individuos que la constituye. Pero no es lo vital: la vida, quiere acrecentarse, elevarse, derrocharse, y esto entraña siempre grandes peligros para el conglomerado de los hombres. "La lucha contra los grandes hombres está justificada por razones económicas, los grandes hombres son peligros, son acasos, excepciones, cataclismos bastante fuertes para poner en peligro lo que fué lentamente fundado y construído" (V. de P., 896). Es innegabie el vitalismo nietzscheano. Innegable también el antibiologismo de su solución en lc que tiene de fundamental. Entonces ¿un vitalismo antibiológico?. Zàrathustra dice: "lo que importa no es la vida eterna, sino la vivacidad eterna".

¿Qué naturalezas fuertes nos ofrecel la historia?. Federico II, el singular Emperadof cgermano quie durantenlas Gruzadas sintió la superioridad del Islam. César Borgia inspirador de uno de los inspiradores de Nietzsche. En la Alemania moderna Bismark, Leibnitz, Haendel y Goethe, que definitivamente los excede y muy particularmente en la admiración de Nietzsche, el qué, contradiciendo alguna afirmación de Zarathustra, llega a llamarlo alguna vez aunque dubitativamente y sin mencionarlo específicamente "Superhombre".

Digámos aquí nuestra palabra sobre el "aristocratismo nietzscheano". El aristócrata es una figura de la vida ascendente. Hay otras que parece considerar inferiores $y$ otras que evidentemente le son superiores. Si habla del aristocratismo y aún de la nobleza del nacimiento y de sangre tengamos en cuenta su "observación para los asnos"; no se refiere a la partícula "Von" ni al almanaque Gotha. (V. de P., 942). Se refiere simplemente al poder que se ha heredado. Si habla de aristocratismo lo hace en un riguroso sentido etimológico: los mejores, los más fuertes, los más ricos: "La verdadera bondad, nobleza, grandeza de ánimo que 
nace de la riqueza, la cual no dá para adquirir no quiere enaltecerse con el hecho de ser benévola" (V. de P., 935).

El noble tiene como cualidades según Nietzsche: asiduidad en las cosas exteriores que limita y preserva; apariencia frívola que guarda de la curiosidad; adialoría; soportar pobreza y enfermedades; convicción de que sólo hay deberes; dizfraz; máscara; capacidad para el ocio; gusto por las formas, cortesía como una de las mayores virtudes; encontrarse bien con las mujeres, los príncipes y los sacerdotes; generalizar difícilmente, amar la ingenuidad y los ingenuos; naúsea de lo demagógico y de la familiaridad plebeya; poco aprecio de los buenos, capacidad de encontrar la gota de oro en los hombres peores, buscar para sí la responsabilidad y crearse enemigos y conciliarse difícilmente, contradecir a la mayoría con las propias acciones, hacer de la castidad la nobleza del sexo que no soporta ni lo brutal, ni lo morboso ni lo prudente; poner en juego los propios, honor vida, salud; y no precisamente por "amor a los hombres". Ser capaz de atacar en línea recta.

El instinto del rango es ya de por/sí indicio de rango elevado, cierto placer en las matices del respeto, "cuyo placer hace adivinar el origen y las costumbres nobles". "La veneración de la Biblia es quizá el más hermoso resultado de la disciplina y la dulcificación de costumbres que Europa deba al cristianismo" (Más allá del Bien y del Mal, 263).

El aristócrata no comprende lacvanidade Le parece de tan mál gusto $\mathrm{y}$ tan irrespetuosa y ridícula "que se siente inclinado a considerar la venidad como una anomalla y a dudar que exista en la "mayor parte de los casos" (Más allá del Bien y del Mal, 262).

Inimaginable es la aristócrata sin egoísmo, sin esa fé en sí mismo que le lleva a pensar que se le deben someter y sacrificar otros egos. En determinadas circunstancias "y después de dudar, confiesa que hay seres con derechos iguales a los suyos y desde entonces se porta con estos seres de su clase como se porta consigo mismo" (Más allá, 265).

El dolor separa, es decir aísla, conduce a la soledad, a la fuerza, aristocratiza. Quien ha sufrido mucho se siente distante, lejano, superior; no quiere ser compadecido, no quiere que su dolor se vulgari. ce al ser trasmitido por la compasićn a cualquier otra persona, siente que es una experiencia única, su experiencia; teme igualmente ser comprendido y por ello ama el disfraz, la máscara.

El sentimiento de unicidad o de muy reducida compañía que caracteriza al aristócrata se expresa también en un sentir envilecer los propios deberes al hacerlos de todos, en "no renunciar jamás a la propia respon- 
sabilidad ni echar a otros la cuipa" y el contar entre los deberes propios los privilegios y su ejercicio.

La multiplicidad y el amor al peligro de las naturalezas aristocráticas constituyen grave riesgo para su pervivencia: la naturaleza garantiza mejor el número y lo que pertenece al número.

La aristocracia vigorosa de los primeros tiempos al refinarse pierde fuerza y se deja llevar por los valores de los débiles; por su generosidad, se interesa por todo lo que es pequeño, se vuelve compasiva. A través de los valores de los débiles, la debilidad la domina.

Nietzsche quiere prevenir contra ello, asi como contra las concepciones muelles de la nobleza - la nobleza al civilizarse pierde nobleza - y encuentra que no se debe prescindir de "un poco de brutalidad ni tampoco de una cierta tendencia hacia la criminalidad"; "se debe ser arriesgado aún contra sí mismo, tentador, corruptor". El designio del filósofo es "crear la atmóstera para un ideal más robusto" y encuentra que las aristocracias que han sido no constituyen refutación de la necesidad de una nueva aristocracia.

El grande hombre es un hombre en el que la naturaleza ha empleado el gran estilo, aquel que se avergüenza de lo placentero, de lo pequeño, que no quiere persuadir sino mandar. Caracteriza a estos hombres "Hacerse dueños de aquel caos que se es; constreñir al propio caos a devenir forma; devenir dógicos, simplesfclaros, matemáticos; devenir leyes, tal es aquí la gran ambición. Con ella se choca a la gente; ya nada suscita amor hacia semejantes hombres poderosos; a su alrededor se extiende un desierto, un silencio, un miedo, como ante el espectáculo de un gran sacrilegio" (V. de P., 842). El grande hombre emplea una larga lógica, que a causa precisamente de su largueza, es poco probable que sea comprendida, engaña sobre sí. Es frío, duro, poco escrupuloso y desdeña la opinión mucho más que el hombre noble. "Si no puede dirigir se queda sólo y entonces sucede que mira con malos ojos muchas cosas de las que encuentra en su camino".

No busca amigos sino criados 0 instrumentos, en sus relaciones con los hombres tiende a dirigirlos. "Cuando no se habla así mismo, prefiere mentir a decir la verdad, para mentir hace falta más espíritu y más voluntad". Es escéptico, pero da la impresión de lo contrario. Esto no significa que no tenga conviciones pues "aún tiene necesidad de ellas pero no se sujeta a ellas". No es un hombre obsesionado por una fé, por una creencia absolutas; es todo lo conirario del fanático tipo Rousseau, Lutero, Savonarola o Rebespierre (el grado de debilidad de nuestra fé se mide por el número de principios sólidos que necesita 
para desarrollarse). El deseo de algo sólido es la expresión de la fatiga, el fatalismo, la decepción o el temor de una nueva decepción o bien la exhibición del resentimiento. el mal humor, el anarquismo exaspera. do" (Gay Saber, 347).

Los grandes hombres son escultores que trabajan con mármol humano: "les excita ver el caos". Su peligro es perecer por el espectáculo del dolor que tienen que causar y porque no son contemporáneos ni de sus semejantes ni de su obra. Pero "No perecer de miseria interior y de incertidumbre cuando se provoca el gran dolor y se oye el grito de este dolor: esto es grande, esto forma parte de la grandeza" (Gay Saber, 325).

El otro peligro de los grandes hombres está en su adaptación precipitada a "deberes, a sociedades, a reglas de trabajo cotidianas" en que el acaso los pone en una época en que la fuerza todavía no ha dictado a la conciencia su ley. Es decir en su modestia, en su altruísmo.

Los grandes hombres son "arcos fuertemente tensos" - las mayorías" tratan de romperlos - hacia el futuro.

El hombre superior es el filósofo del porvenir, el creador de valores en quien se revela la más alta y espiritualizada Voluntad de Poder, él es quien manda aunque no ejerza el poder. Utiliza como trabajo preparatorio el de los hombres de ciencia, hace extraordinarios esfuerzos para experimentar Ba gue altura puede elevarseall hombre. Por requerir de una alta herencia de fuerza, el filósofo debe surgir en alianza con una casta dominante como su expresión más espiritualizada.

"Muchas generaciones han de preparar el advenimiento del filósofo: cada una de sus virtudes ha de ser adquirida, c:altivada, heredada e incorporada: no sólo el fluir ligero y delicado de su pensamiento, sino también y principalmente la sincera disposición a las grandes respon. sabilidades; lo imperioso de la mirada; la separación del vulgo y de sus deberes y virtudes, la protección y pronta defensa de todo lo mal interpretado o calumniado, de Dios o del díablo, la satisfacción y administración de la justicia grande; el arte de mandar, la amplitud de la vo. luntad, el ojo reposado que rara vez se admira, que rara vez se humilla, que rara vez ama".

La historia de la filosofía nos muestra "una gran cantidad de casos fallidos y de progresos extraordinariamente lentos". El ruido de los pequeños y de su coloquio nos oculta a menudo a los pocos verdaderamente grandes. 
Los filósofos del porvenir representan y crean la jerarquía. Se distinguen de los "heroes, mártires, genios y entusiastas" en que son más "calmosos, pacientes, finos, fríos, y lentos (V. de P., 993). Al determinar los valores y guiar la voluntad de rnilenios dirigiendo las naturalezas más elevadas, son los hombres más elevados. A ellos les debemos los más grandes sucesos - las más grandes ideas, las que no crecen en la plaza pública - las que mueven al mundo pero llegan "con piés de paloma".

Es tarea de la historia la creación de la especie má salta de hombres de la que salga el Superhombre que la justifique y son los filósofos con sus evaluaciones y leyes los que harán posible tal aparición. Pues los filósofos del porvenir deberán ser legisladores y educadores; pero "Un educador no dice nunca lo que piensa, sino lo que piensa de una cosa en relación con la utilidad de aquel a quien educa". Aquí Nietzsche no sólo declara su maquiavelismo de siempre, sino que parece estar influído por Platón quien reconoce el libro III de la "República" el derecho de los magistrados a mentir. Se trata pues de educación más allá del bien y del mal, con los mismos medios "inmorales" de toda gran educación cuyo éxito reposa precisamente en la habilidad del educador para mentir bien.

Estos hombres superiores obligarán a la voluntad de los siglos a abrir nuevos senderos "'y enseñaránal hombre que su porvenir está en la voluntad y que de su voluntad depende el preparar grandes empresas para poner" termino a la horrible dominación del contrasentido y del acaso que hasta el día de hoy se llama historia" (Más allá, 203). Resumirán en un sólo hombre al sacerdote, al médico, y al educador contemporáneo. Su mira será la de acumular fuerzas primero y después señalar las evaluaciones y la tarea que las guiarán. En este sentido la doctrina nitezscheana es eudemonista, en cuanto todo abrir un campo de actividad, el que fuere a una gran concentración de poder sin empleo, trae consigo felicidad.

En estos filósofos el designio del hombre se apropiará la aspiración de la vida: superarse en la grandeza y la sobrehumanidad. Y sólo los grandes podrán crear a los más grandes, tomando como punto de partida de sus evaluaciones el porvenir, ese porvenir que no han sabido mirar los filósofos, huérfanos de sentido histórico y que los socialistas han confundido con el futuro bienestar de las masas. 


\section{VI.- EL SUPERHOMBRE (I)}

"Es preciso que vengan los leones $\mathrm{r}$. sueños" (Zarathusira IV, 11).

SUMARIO. -El Superhombre, un símbolo.- Las contradicciones en el Superhombre. -El Superhombrs no es una nueva especio biológica.- Sentido vilalista y antibiológico del Superhombre. -El Superhombre no ha sido realizado jamás.

Las figuras de la vida ascendente encuentran su culminación en el Superhombre. La dificultad, lejanía y máximo vigor del sobrehumano, ha llevado a algunos estudiosos a negar que Nietzsche pensara en la posibilidad de su efectiva existencia; vendría a ser solamente un "mito" que hubiera dicho Sorel, una imagen. propulsora, pero irrealizable, una como sonriente novia imposible, apetecida, para que obrase sobre ellos efectos parecidos a los que el retorno tuvo en el propio Nietzsche. Más aún, se ha renunciado a la posibilidad de describir el Superhombre.

Un mito, es decir, más que un ideal, es innegable que fuera también esto, pero un mito es precisamente también una esperanza; en este caso la esperanza más alta del hombre que quiere vivir el sentido de la tierra en quien viendráa otorgarlo que vendrá con la mayor necesidad que es posible en el mundo de contingencia que es el real. Una "fórmula", un "símbolo" lic liama Nietzsche, Pèro esto no autoriza a hacerlo descender de rango, a colocarlo como un ideal irrealizable e informe.

Es innegablemente una de las imágenes más vulgarizadas de nuestro filósofo, pero al mismo tiempo, de las menos comprendidas, como lo prueba la renuncia que se ha hecho a interpretarlo - por ejemplo por H. Lefebvre - y el entender que es bastante ya el esbozar una serie de presuntas caracterizaciones hechas por Nietzsche mismo, varias de ellas opuestas e irreconciciables. Se ha dicho que Nietzsche se ha guardado de limitar al sobrehumano y de hacerlo descender al rango histórico-social. "No ha descrito este hijo apenas concebido, hijo del devenir y de la eternidad", dice el autor mencionado.

Pero no se debe renunciar a esa interpretación, pues las contradicciones son más que de Nietzsche al describir al Superhombre, del Superhombre mismo que es la antípoda del "lisiado al revés" es decir, que representa al máximo desarrollo de cualidades antagónicas. No se pue- 
de negar, sin embargo, que la falta de una mayor uniformidad en la descripción de parte del propio Nietzsche no ha ayudado precisamente a desvanecer la confusión sobre este punto.

Queremos comenzar por hácer una connotacićn negativa:

1) El Superhombre no es una nueva especie biológica.

La innegable, pero pasajera, influencia de Darwin sobre Nietzsche, que aparece demasiado acentuada en algunos divulgados pasajes del Zarathutra, ha llevado a concebir al Superhombre como una nueva especie biológica, cuyo advenimiento se produciría por evolución de la humana.

"Hasta ahora todos los seres han dado de sí algo superior a ellos $\mathrm{y}$ vosotros ¿queréis ser el reflujo de ese gran flujo y volver a la bestia mejor que superar al homire?".

"¿Qué es el mono para el hombre? Una irrisión o una vergüenza dolorosa. Pues eso es lo que debe ser el hombre para el Superhombre: una irrisión o una vergüenza dolorosa".

"Habéis recorrido el camino que media desde el gusano hasta el hombre y aún queda en vosotros mucho del gusano. En otro tiempo eráis monos y ahora el hombre es todavía más mono que ningún mono" (Zarathustra, Prólogo, III). bre".

"El hombre es una cuerda tendida entre la bestia y el Superhom-

"Nuestro camino va hacia arriba, de la especie a la especie superior" (Zarathustra "I, 23\%, Puccinelli Converso"

"Y será el gran mediodía cuando el hombre esté a la mitad de su trayecto entre la bestia y el superhombre y celebre como su esperanza suprema su camino hacia el ocaso: porque será el camino hacia una nueva mañana" (Zarathustra I, 23).

Pero al otro lado de estos párrafos que parecen señalar en Nietzsche su creencia en "la evolución de las especies", la diferencia con el pensamiento de Darwin, a la que ya nos hemos referido, aparece en obras posteriores de Nietzsche (Particularmente en "El Crepúsculo de los ídolos" y en "La Voluntad de Poder"), en las que su pensamento se fija más nítidamente.

"Se sostiene que la evolución de los seres vá madurando contínuamente. Esto carece de todo fundamento. Cada tipo tiene sus límites: más allá de estos no hay evolución.

Mi opinión de conjunto: Primera proposición: el hombre como especie no ha progresado. Se alcanzan, sí, tipos superiores pero no se conservan. El nivel de la especie no se eleva. 
Segunda proposición: el hombre como especie no representa un progreso frente a cualquier otro animal. Todo el mundo vegetal y animal no se desarrolla desde lo más bajo a lo más alto. Por el contrario todo se desarrolla contemporáneamente, una cosa sobre la otra y a través de la otra y contra la otra. Las formas más ricas y más complejas - porque la palabra tipo superior no quiere decir nada más que eso - perecen con facilidad, sólo las inferiores conservan una aparente inmortalidad. Los tipos superiores son conseguidos rara vez y se mantienen con dificultad: los inferiores tienen la ventaja de una comprometedora fecundidad. También en la humanidad perecen más fácilmente, con alternativas de fortuna y desgracia, los tipos superiores, los casos felices de la evolución. Estos están expuestos a toda especie de decadencia. Son extremos y casi por esto son ya decadentes. La breve duración de la belleza, del genio de un César, es "sui géneris", estas cualidades no se transmiten por herencia. Se heredi el tipo; un tipo no es cosa extrema, no es un "caso féliz". Esto no depende de una especial fatalidad o mala voluntad de la naturaleza, sino simplemente del concepto de "tipo superior"; el tipo superior representa una compleiidad incomparablemente mayor, una suma mayor de elementos coordinados, por consiguiente también la disgregación es incomparable más probable. El "genio" es la máquina más sublime que existe, por consiguiente la más frágil.

Tercera proposición: la domesticación ("a "civilización") del hombre no llega a muchaJprofundidadin Alli dondepenetra en profundidad se convierte súbitamente en degeneración (tipo el cristiano)" (V. de P., 684).

Pero sobre todo Nietzsche insiste en su interpretación de la lucha por la vida opuesta a la de Darwin:

"Si se quiere reducir la realidad a una fórmula moral, esta moral dice así: los tipos medios tienen más valor que las excepciones, los seres de decadencia más que los medios; la voluntad de la nada sobre la voluntad de vencer; y el objeto complexivo es, para expresarnos en términos cristianos, budísticos, schopenhauerianos: antes no ser que ser".

"Yo veo a todos los filćsofos, yo veo a la ciencia de rodillas ante la realidad de una lucha por la vida opuesta a la enseñada por la escuela de Darwin; o sea yo veo predominar a los que comprometen la vida, el valor de la vida. El error de la escuela de Darwin ha llegado a ser para mí un problema; ¿Cómo se puede estar tan ciego para ver en falso precisamente en este punto? 
Que las especies representan un progreso es la más absurda afirmación del mundo; por ahora estas representan un nivel. Que los organismos más altos se hayan desarrollado de los más bajos no ha sido demostrado hasta ahora por ningún ejemplo".

2) El Superhombre no es ningún grande hombre del pasado ni ha sido realizado jamás.

"Jamás ha habido un Superhombre. Yo he visto desnudos a todos los hombres, al más grande y al más pequeño" (Zarathustra II, 4). Pero ha habido pueblos precursores del sobrehumano, momentos de la historia ocupados por la vida ascendente:

a) Los primitivos germanos, los señores europeos de la protohistoria, los ejemplares de esa "fauve blonde" de los que Nietzsche se expresa con tanta admiración en la "Genealogía", han sido considerados por nihilistas neonietzscheanos - los Baeumler, Juenger, Moeller, Van der Bruck, Niekish - con deseo de servir a determinada ideología política, como representantes del sobrehumano. Pero Nietzsche ve en estas "bestias rubias", figuras primitivas de la vida ascendente, pero en ningún caso "Superhombres protohistóricos". Esto es usar mal los términos. Las evaluaciones señoriales protohistóricas, en algún sentido han de ser restauradas, pero Nietzsche que no cree en el progreso (que interpreta antes bien como el "camino" de la decadencia) no carece de sentido histórico como lá gran mayofía de los filósofos, a los que por esto mismo, dirige tan fuertes reproches. Un proceso de "interiorización" ha comenzado"por debilitar al hombre, "peró los órganos que ha creado, pueden devenir instrumentos precisamente de una mayor Voluntad de Poder, antes imposible por su ausencia. La Voluntad de Poder es organización de cualidades cada vez más diversas y en la vida ascendente lo que no mata fortalece. La resurrección de ese tipo no es pues ni posible, ni deseable y no importa la predilección con que Nietzsche se refiera a él en uno de sus libros de más marcado tono polémico. Las cualidades de la "bestia rubia" habrán de venir pero en un. grado más elevado. Las pasiones al intelectualizarse, al espiritualizarse luchan contra sus grados inferiores, esto lo sabe el filósofo: "Todas las pasiones tienen un momento en que son sencillamente funestas, en que oprimen a sus víctimas con el peso de su estupidez, y un mo. mento posterior, bastante más posterior en que se desposan con el espíritu, se espiritualizan" (Crepúsculo, V, 1).

La "fauve blonde" debe ser considerada como una manifestación prehistórica -o protohistórica- de la vida ascendente. Nietzsche pre- 
cursor del sicoanálisis trata de hacernos admirar sus instintos, sabedor de que ya no podemos tenerlos, de que ya ni seremos ni deberemos ser como ellos. Pero, ni aún en este caso, se ha referido a la fuerza física que, como anota el griego Calicles, es precisamente característica de los esclavos: "La casta aristocrática fué siempre en sus comienzos la raza bárbara y su preponderancia de be buscarse no en la fuerza física sino en la fuerza del espíritu: eran hombres más completos (bestias más completas)" (Más allá, 257).

Si en alguna parte nos habla de "bárbaros del porvenir" insistirá en que se trata de "bárbaros domesticados". Todo el mecanismo de la "sublimac:ón" - explicitado después por el sicoanálisis - en Nietzsche. Es pues una imagen histórica, de la que piensa que pueden venirnos algunas sugestiones pero que no entra dentro de las que nos ofrece una solución como ejemplo. Además, la bestia rubia sublimada o espiritıalizada ya no es la bestia rubia cruel y sanguinaria de la prehistoria. Es el hombre culto, la persona, el gran hombre, el hombre superior. La bestia rubia es un lejano escalón, hundido en el pasado, hacia el sobrehumano. En todo caso una profecía. Nada menos. Nada más.

b) Los indos ganan su admiración como ganaron la de Schopenhauer, pero por otros motivos; Nietzsche no escatima elogios al Código de Manú en particular a la ordenación de las castas: "La naturealeza y no Manú es la que separa alas castas que dominan por su entendimiento". "En "foda sooiedad sana se distinguen tipos que fisiológicamente tienen una significación diversa". "Una gran civilización es una pirámide" (Anticristo, 57).

c) En el Antiguo Testamento encuentra que "los personajes, las castas, los discursos, todo, son de un estilo grandioso. No hallamos en la literatura griega ni en la India nada parecido. Nos detenemos sobrecogidos de terror y de veneración al vislumbrar lo que fué el hombre" (Más allá, 252). Una figura particularmente señalada de la vida as. cendente es Nemrod, el "vigoroso cazador delante de Jehová" (Génesis, 9). Esta etapa robusta y breve se convierte en su contraria por la trasmutación judaica de todos los valores que Nietzsche denuncia.

d) No existe ningún camino que siga el hombre inconscientemente, sin percatarse de su más íntimo significado, guiado en realidad por la mano de Dios como aparece en la filosofía de la Historia del gran escritor y moralista ruso que se señala como antípoda de Nietzsche (en "La Guerra y la Paz"). "En 2500 años no nos hemos hecho mejores: no 
estamos a la altura del hombre del Renacimiento ni el hombre del Renacimiento estuvo a la altura de los griegos.

El filósofo Nietzsche - un mal latinista pero un excelente helenista cuando estudiante - siempre sintió la atracción del admirable pueblo griego y fué el primero "en tomar en serio aquel fenómeno maravilloso que lleva el nombre de Dionisios" sin el cual los helenos le parecen incomprensibles, (el mismo Goethe, por no tenerlo en cuenta no los comprendió, como tampoco Wincke!mann nos dice).

En los misterios dionisianos se expresa el hecho fundamental del instinto griego, su "voluntad de vivir". "Para los griegos el símbolo sexual sué el símbolo venerable en sí, el verdadero sentido profundo dentro de toda la religiosidad antigua. Todo detalle en el acto de la generación, del embarazo, del nacimiento, despertaba los sentimientos más altos y solemnes", "sólo el cristianismo que tiene en su base el rencor contra la vida ha hecho de la sexualidad una cosa impura: cubrió de fango el principio, la premisa de nuestra vida" (Crepúsculo, X, 4). Es por "su más fuerte instinto, la voluntad de poderío" que deben ser estimados los griegos y no por sus filósofos como hacen los alema. nes. Los filósofos son los decadentes de Grecia, el movimiento contrario al gusto antiguo y noble (contrario al instinto agonal, a la polis, al valor de la raza, a la autoridad, a la tradición)" (Crepúsculo X, 3).

Platón es un mixtificador de especie superior esto es, un idealista, un "poltrón frente a ta realidad"; contra él destaca Nietzsche el valor de Tucídides con el cuajela cultura del los sôfistasono sea de los realistas, llega a su completa expresión", constituye "la última revelación de aquella fuerte, severa, dura objetividad que había en el instinto de los antiguos griegos" (Crepúsculo $\mathrm{X}, 2$ ).

No se puede negar la importancia que tuvo la esclavitud en la producción de la filosofía, forma superior del ocio hecha posible por ella, que posibilitó también aquel "pathos de la distancia" "tan indispensable a la verdadera grandeza y a la verdadera nobleza". "Esta altivez se ha hecho extraña e imposible para nosotros. Ni siquiera como símbolo posee para nosotros la palabra "esclavo" toda su intensidad" (Gay Saber, 18).

Los presocráticos vivían los instintos griegos en su mayor pureza, en su mayor fuerza, en su mayor elevación: Empédocles, Anaxágoras y sobre todo Heráclito. Empédocles el notable taumaturgo, médico, filósofo etc., desdeñó la corona de su ciudad natal y mereció el que nuestro filósofo compusiera un drama titulado con su nombre que no fué terminado. Anaxágoras está cerca de Nietzsche por su pluralismo cuantitati- 
vo que no llega a ser un atomismo. Heráclito tiene el lugar preferente en la estimación del pensador: "Cuando el resto del pueblo filosófico rechazaba el testimonio de los sentidos porque estos nos hacen ver multiplicidad y cambio, él refutaba su testimonio porque estos muestran las cosas como dotadas de duración y de unidad". "Tendrá eternamente razón al sostener que el Ser "es una ficción vacía" (Crepúsculo III, 2). "La afirmación del pasar y aniquilarse que es decisiva en la filosofía dionisiaca, la aprobación del contraste y de la guerra, el devenir, con la radicai renuncia al concepto mismo de ser, son todas cosas en que yo veo en todo caso lo que hay de más afín a mí en cuanto hasta ahora se ha pensado (Ecce Hoino-Capítulo "El Origen de la Tragedia").

Los sofistas representan más tarde el realismo, formulan los valores y elevan las prácticas de la época al rango de valores' tienen la valentía peculiar a todos los espíritus vigorosos de conocer su inmoralidad". "Los sofistas eran griegos, cuando Sócraies y Platón tomaron el partido de la virtud y la justicia eran judíos o yo no se qué". Nietzsche rechaza algunos intentos de hacer aparecer a los sofistas como personas morales. Su valor está precisamente en que no lo fueron, nos dice: "Todos los grandes caracteres de la antigüedad han considerado con repugnancia a los filósofos de la virtud: en ellos veían querellistas y cómicos (juicio emitido sobre Platón por Epicuro, por Pirrón)" (V. de P., 434). Una doctrina de la "salvación del alma", de la felicidad, de la virtud expresa una naturaleza en decaiencia instintos debilitados y anarquizados. ¡Qué diferencia con los filósofos que precedieron a Sócarles! Son personajes distinguidos ho dialécticosode plaza pública, están "aparte del pueblo y de las costumbres, han viajado mucho, con la mirada lenta, instruidos en los asuntos de Estado y en la diplomacia. Ellos anticipan sobre los sabios todas las grandes concepciones de las cosas: representan elics mismos esas grandes concepciones: ellos mismos se hacen sistema" (V. de P., 437). "La dureza creciente es griega: fuerza de los sentidos, cinismo, lo inhistórico, lucha, sentimiento contra lo bárbaro; odio contra lo indeterminado, informe, abovedado; la sencillez de la manera de vivir, crear dioses como su más alta sociedad" (Fragmentos de Filosofía General, V, 4).

Posteriormente Pirrón, Epicuro y los escépticos en general, aunque figuras honestas y hasta venerables, no le parecen a Nietzsche manifestación de la vida ascendente sino antes bien de decadencia: son los budistas griegos.

e) Los romanos le parecen a Nietzsche representar la más grandiosa forma de organización en circunstancias difíciles hasta ahora rea- 
lizada", en comparación, con la cual todo lo anterior, todo lo posterior, es artificio, chāpucería, dilettantismo". "Fué una admirable obra de arte de gran estilo, fué un comienzo, su construcción estaba calculada para demostrar su bondad en miles de años; hasta hoy no se constru. yó nunca así, ni siquiera se soñó en construir en igual medida "sub es pecie aeterni" (Anticristo, 58). Roma fué verdaderamente la mayor rea-

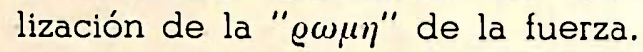

¡Griegos! ¡Romanos! ¡Ĺa nobleza de instinto, el gusto, la investigación metódica, el genio de la organización y de la dministración, la creencia y la voluntad de un porvenir para el hombre, el gran sí a todas las cosas visibles en calidad de "imperium romanum" visible a todos los sentidos, el gran estilo que no era ya simplemente arte sino que se había convertido en realidad, caridad, vida" (Anticristo, 59).

f) La brillante civilización de Provenza, aplastada por herética, sociedad aristocrática supo ya del "Gay saber" en sus caballeros poetas "a los cuales Europa debe tanto" (Más allá del bien y del mal", 260).

g) El mundo morisco de la cultura, mundo noble, "debía su nacimiento a instintos nobies y viriles" y "afirmaba la vida con los más raros y preciosos refinamientos" (Anticristo, 60). Uno de los muchos motivos de la admiración de Nietzsche por Federico II "aquel genio entre los emperadores alemanes" es que hubiera comprendido la civilización del Islam, con la que supo hacer la paz.

h) El Renacimiento és quizáda época que despierta admiración mayor en el filósoto - a pesar de la preferencia por los griegos (que declara por ej. en "la voluntad de Poder, 881, 882).- Vé en él la trasmutación de los valores cristianos, es decir un movimiento precursor de lo que el mismo Nietzsche representa: "no ha habido posición de problemas más decisiva que la obrada por el Renacimiento, mi problema es su problema". (Anticristo, 61). En la misrna sede de los valores de decadencia, "la tentativa hecha por todos los medios, con todos los instintos, con todo el genio, para conducir a la victoria los valores contrarios, los valores nobles" (Anticristo, 61). Piensa Nietzsche - parece que recibiendo el error de Burkhardt - que el Papado sería recibido en herencia por César Borja. "Todas las divinidades del Olimpo habrían prorrumpido en una carcajada inmortal, ¡César Borja, Papal ¿Se me entiende?" (Anticristo, 61). Los modernos habrían ofrecido a los contemporáneos de César Borja "una comedia supremamente ridícula" "nosotros no podemos colocarnos. ni siquiera imaginarnos en la situación del Renacimiento: nuestros nervios no soportarían aquella realidad para no hablar de nuestros músculos" (Crepúsculo, IX, 37). La censura 
moral contra este gran virtuoso, luético representante de la vida ascen dente, le hace reir (V. de P., 871). Ni ocioso ni desenfrenado, le parece ejemplo de ese autodo:ninio que marca el gran contraste con el vicio $y$ el desenfreno. Nietzsche observa que en el Cielo no hay hombres interesantes.

\section{VIL- EL SUPERHOMERE (II)}

SUMARIO.- Poder y sobrchumanidad-El superhombre, sintesis-Derechos del Superhombre.- El Superhombre no debe ser juzgado por sus efectos. - El Superhombre como fin de la humanidad.- Autodominio en el Superhombre.- El peligro, potencializador de la vida.- Lo benévolo y lo morboso en el sobrehumano.- El Supcrhombre y transmutación de los valores. - El cuerpo, la: salud y la enfermedad.- El "mundo pequeño".- Interpetación nietzscheana del progreso.- El Superhombre y "el mal".- El Superhombre y los valores. - El Superhombre y el retorno.- El Superhombre y el pasado.

\section{Biblioteca de Letras}

Siendo las cualidadesg de podèn dasi quendeterminan la jerarquía, la mayor corresponde al mayor poder: "La superlativa elevación de la conciencia de fuerza en el hombre es lo que crea el Superhombre" (V. de P., 1060). "Porque nuestra fuerza es la que dispone de nosotros y el miserable juego espiritual de fines o intenciones y motivos es sólo una apariencia aunque los o;os débiles vean en él, la cosa en si", (V. de P., 995). Es la gran pasión, la más vigorosa expresión de la Voluntad de Poder, la que determina el "gran estilo" en el carácter y la tarea social del sobrehumano.

El común de los hombres tiene en contados momentos, por breves instantes, estados de alma elevados (unos pocos, raros hombres los tienen más duraderos). En el sobrehumano se dará "Como estado habitual, este estado excepcional que nos emociona: un contínuo vaivén entre lo alto y bajo, un sentimiento de alto y bajo, de subir constantemente escalones y al mismo tiempo de volar sobre las nubes" (Gay Saber, "288). 
Contra la mediocridad oue Nietzsche refiere a la unilateralidad, el Superhombre aparecerá como el "gran hombre sintético, adicionador". Sólo siendo campo de muchas cualidades diferentes y contradictorias, y de su lucha, y del ienso dominio de una de ellas es concecible la sobrehumanidad. Para nuestro filósofo el hombre más alto sería "el que representase con mayor fuerzà el carácter contradictorio de la existencia, como gloria y única justificación de la existencia misma"; los hombres comunes, perecen pronto cuando crece la multiplicidad de los elementos y lá tensión de los contrastes, o sea la condición preliminar de la grandeza del hombre" (V. cle P., 881). O sea dicho "en términos morales": "Es necesario que el hombre se haga mejor y más malo" (Zarathutra, III, 13).

$Y$ si el mundo en el que aparece el sobrehumano puede ser de mediocres especializados, de "lisiados al revés", ellos estarían formando esta gran masa humana que le servirá de base vital, compuesta de humanos, degenerados hasia ser nada más que una función. La "humanidad" sería "un enorme sistema de ruedas, de ruedas cada vez más pequeñas, cada vez más sutilmente adaptables". Algunas filosofías, en particular la kantiana han llegado a valorar esta forma de existencia como la más alta, la más estimable moralmente. Scheler incide en esta apreciación cuando se refiere a la "traición a la que hemos de inculpar el falso heroísmo del trabajo $\mathrm{y}$ del deber que han sido enseñados en toda su amplitud da pärtir de Kant" (Etica-Prólogo a la $2^{a}$ ed.).

De los humanos "la mayor parte repersentan al hombre en calidad de fragmentós brde detalles; sólo sumándolo's juntos sale un hombre", pero quizá forma parte de la economía de la evolución humana, nos dice Nietzsche, que el hombre se desarrolle por fragmentos, ensayos - "La sociedad humana es una tentativa" ("Zarathustra, III, 12,25), no un contrato - de cuyo juego de conjunto nace a veces el hombre completo, el hombre "piedra miliar" zue' muestra hasta que punto ha llegado al humanidad. Esta no avanza de un sólo golpe: "con frecuencia el tipo ya realizado se pierde de nuevo". (V. de P., 881). Pero en ciertas circunstancias "un individuo sólo, puede justificar la existencia de milenios enteros" (V. de P., 997).

En esa administración colectiva de la tierra que nos anuncia Nietzsche, el Superhombre aparecería para darle un sentido, una orientación, un fin. Perteneciente a una especie más fuerte como su tipo más alto encuentra en aquella mecanización la base vital y. social para su propia eleveada existencia. Nietzsche combate el "optimismo económico" que cree qe aumentando los gastos de todos debe crecer la unidad, pues 
Io cierto es que "el hombre se hace menor: tanto que no se sabe para que ha podido en general servir este monstruoso proceso" (V. de P., 886).

Siendo sinónima de riqueza la multiplicidad, el Superhombre tendrá "todos los rasgos morbosos del alma moderna" pero será lo suficientemente fuerte "para transformarlos en pura salud" (V. de P., 905). Sin embargo en el ánimo del precursor aparece la duda de que se pueda enseñorear está enorme complejidad: de allí el escepticismo que invade a menudo al hombre superior que prepara con nuevas evaluaciones y leyes y medidas educativas, el advenimiento del Superhombre que se deberá en parte a circunstancias provocadas, en parte a acasos favorables. Más forma parte también de la labor a cumplir la lucha contra este escepticismo.

Nietzsche nos reitera el pensamiento de que la desigualdad de derechos es justicia. El Superhombre tendrá los máximos derechos porque tendrá sobre sí la mayor tarea: la justificación de la existencia del hombre, el otorgar un sentido a la historia y a la vida.

Nuestro filósolo se pone también en el caso de la ausencia de grandes hombres en determinado momento: entonces el pueblo tiende instintivamente hacia los hombres o semi-dioses del pasado. La aparición e intensificación de las religiones prueba así la ausencia de hombres grandes en el momento en que se produce. (V. de P., 875).

No vayamos a imaginar que la justificación del Superhombre sea la de justificar la historia, es decir, la vida de otros hombres: este es un efecto secundariol blalgrandeza yla sobrehumanidad no deben juzgarse por sus efectos rostos podrían ser los más terribles - siempre z la grandeza va unida cjerta terribilidad (V. de P., 1028). ¿Porqué no podría precisamente el hombre, del cual salieron los efectos más ruinosos, ser el vértice de toda especie humana, tan alto, tan superior que todo se arruinara por envidia hacia él?" (V. de P., 877). Pero tampoco debe desligarse de toda clase de efectos porque entonces tendríamos una figura de tipo individualista que no es la que ha trazado Nietzsche y contra la cual antes bien, nos previene. (En este error caen Pfänder y Stern entre otros). Los efectos del Superhombre no nos deben servir para medirlo, menos aún la apreciación de los mismos según la moral cristiana; pero aunque viviendo para sí, no se debe separar del sobrehumano cierta magnitud de las acciones, consecuencia de la vigorosa sobreabundancia vital y especialmente el dominio de los demás hombres al que tenderá, así lo lo logre. Nietzsche habla de jerarquía 
en el sentido literal del término y a través de ella es que entiende superar la oposición individualismo-colectivismo, no sólo por destacar que sólo algunos pocos individuos cuentan. La soledad es una escuela y "una patria" para el Superhombre; pero éste se debe también a sí mismo es decir a esa vida que es y que quiere expandirse, verterse, dominar, relacionarse" de arriba abajo".

La sobrehumanidad no estará constutuída "de una raza de señores cuya misión se agote gobernando", sino de una raza que tenga una propia esfera de vida, de un exceso de fuerza para la belleza, el valor, la cultura, las maneras en el sentido más espiritual, una raza afirmadora que se pueda conceder todos los lujos, bastante fuerte para no tener necesidad de la tiranía del imperarativo de la virtud, bastante rica para no tener necesidad ni de la parsimonia, ni de la pedantería," más allá del bien y del mäl, una estufa para plantas raras y elegidas" V. de P., 898).

Pertenece al sobrehumano el "negar el mérito, pero hacer lo que está sobre todo elogio y aún sobre toda comprensión (V. de P., 913). No sigue los propios sentimientos así se trate de actos generosos y heroicos. Nietzsche no concede más valor a estos impulsos de momento entre otras cosas porque todos los hombres son más o menos iguales en lo de seguirlos. El grado más alto le parece a Nietzsche el vencer el propio impulso y realizar el acto fríamente, sin el hedonismo que hay en todo dejarse llevar por los propios impulsos.

Ceder a una pasión és causa deles mayores males. "La grandeza de carácter no consiste en no poseer estas pasiones; por el contrario se poseen en grado terrible, consiste en tenerlas de là brida, y también en hacerlo sin expehimentar placer en frenarlas, sino solo porque. (V. de P., 928). Es por este máximo autodominio -el dominio que sobre todas las pasiones tiene la más espiritualizada y vigorosa de ellas al actuar a través del yo - que se requiere de la larga educación de la voluntad que Nietzsche pensaba que se obtiene por un ascetismo renovado y laico. El Superhombre es la máxima posibilidad de la voluntad.

"Dar la vida por una causa" es fase muy sonora, pero la vida se da por muchas cosas y esto no altera el valor de la cosa. Pero el peligro - tanto "en la calle como en el corazón" - provoca una potencialización de la vida; de allí el ¡Vivid peligrosamente!! ¡¡Estableced vuestros hogares junto al Vesubio!!. La guerra es el gran instrumento de robustecimiento; el Superhombre siempre está en guerra: sino contra alguién, viviendo la tensión de la guerra de sus potencias. 
La guerra nos impide descuidar la violencia y la astucia, y el poner la muerte cerca de los intereses por los que se combate, nos hace honorables.

La benevolencia es, en general, inconveniente, así como el trato de los benévolos, pero puede tener valor cuando acompaña a una gran plenitud vital: el caso del Superhombre. Hay un benefactor que no es desinteresado, sino sclamente rico, tan rico que no puede menos que dar. El Superhombre, si benefactor sería de esta clase. El bien aparecería en él como "lujo, refinamiento, vicio" (V. de P., 934). La veracidad puede también ser honrada como un lujo desventajoso y noble. La riqueza de personalidad es la premisa de esta bondad, cuyo tipo es la disipación, pertenece también a esta riqueza el gran amor de sí, la gran fé en sí, la gran estimación de sí mismo del Superhombre. "Por encima del "tú debes" está el "yo quiero" (los héroes); por encima del "yo quiero" está el "yo soy" (los dioses de los griegos). Los dioses de los bárbaros no expresan nada del gusto de la medida, no son simples ni ligeros ni poseen la medida" (V. de P.; 940).

Después de un largo proceso de esclavización de la naturaleza, el hombre se ha hallado dueño de un exceso de fuerza, entonces dispone de ocio y se encuentra además con que ha superado muchas virtudes que ya no son necesarias, por ello las abandona; impuestas en circunstancias terribles sirvieron, sin embargo, para enriquecer el alma del hombre, aunque su efecto inmediato fuera, peor que sufrimiento y muerte, fenómenos vitales, debilitamiento de los hombres. En cuanto aumentan la multiplicidad del hombre, al ponerse-al servicio de una voluntad superior, se hacen riquezarguerza.ccinelli Converso»

No se debe tratar de separar la grandeza de alma de la grandeza intelectual, nos dice Nietzsche: la primera quiere la independencia, pero provoca abusos si no va acompañada de la segunda. El Superhombre posee ambas. En "el fuego solar de la sabiduría el sobrehumano baña la alegría de su desnudez" (Zarathustra II, 21).

El Superhombre es el fin del hombre, no la humanidad. El Superhombre es también fin de la trasmutación de los valores. ¿Qué logramos con ella? Dar conciencia, buena conciencia, a todas las cosas buenas, a todo lo espontáneo y fuerte conseguido hasta hoy y que no puede desarrollarse suficientemente al sufrir la hostilidad de las valoraciones cristianas. La trasmutación de valores aparece así como un medio al servicio de la vida, al serlo para el logro de su expresión más alta. La trasmutación de los valores la ha sentido necesaria Nietzsche, porque había visto la gran concentración de fuerza y de materia explo- 
siva que sutría bajo los a.ltiguos valores. El Superhombre es "el relámpago de la sombía nube que es el hombre" (Zarathustra, Prólogo, 7).

No se debe olvidar que se trata de la tierra y del sentido de la tierra. Nietzsche rechazaba en la religión el que no hubiera en ella lugar para la creación de valores, que aparecían como dados por algún Dios. Nuestro filósofo entiende restituir al hombre su riqueza y su fuerza mayores al reconocerle su capacidad de crear valores. Y si no puede crear también un Dios puede crear un sobrehumano: "¿Sabríais vosolros crear un Dios?" ¡No me habléis pues de ninguno de los diosesl Sin embargo, vosotros podriáis crear el Superhomrbe" (Zarathustra II, 2). "Debemos colocar de nuevo como un "en si" tras de la evolución, las formas finales de la evolución" (V. de P., 709).

Porvenir, el Superhombre justificaría el sacrificio del presente: "Amo a los que no buscan tras de las estrellas una razón para perecer - para ofrecerse en holocausto; a los que se sacrifican a la tierra para que un día la tierra pertenezca al Superhombre" "Zarathustra, Prólogo, 4).

Nietzsche se pronuncia contra el desprecio del cuerpo cuyo floración le parece criterio de acierto; el espíritu - ese "aparato de sutilizar y empequeñecer" que "sólo es espíritu hasta cierto punto" - vale sólo como su expresión. Lo que no debe confundirse con una hipervaloración de la salud, que aparece como un valor biológico inferior al de la vitalidad quel se bbtendría capitalizando favorablemente una en. fermedad. "Tenemos necesidad del locanormal damos un gran "choc" a la vida mediante estas grandes enfermedades" (V. de P., 778). Pero nada en el Superhombre que sepa a una grandeza del espíritu a expensas de los sentidos. "La fuerza y el poder de los sentidos es la cosa esencial en un hombre bien formado y completo: ante todo, debe formarse el magnífico animal ¿Qué importa toda humanizaciónl" nos dice extremando la expresión de este parecer. (V. de P., 1045). El Superhombre se kalla en realidad más allá de la oposición espíritu-sentidos: "el espíritu está en los sentidos como en su casa, como los sentidos están en el espíritu suyo, también familiarmente y todo lo que se desarrolla en el espíritu debe también desencadenar en los sentidos una extraordinaria y delicada felicidad". "Es verosímil que en tales hombres bien constituídos, las vicisitudes más sensuales terminen por ser transfiguradas por una embriaguez de imágenes propia de la más alta intelectualidad: ellos sienten en sí una especie de divinización del 
cuerpo" (V. de P., 1051). Así el sabio y el animal se juntan para producir este tipo superior. (Tratados filosóficos, VII, 1).

No es tampoco el Superhombre una mayor conciencia, no represerita "un progreso en la conciencia". Nietzsche habla de la equivocación de considerar el estado consciente como el más perfecto". "Es preciso que busquemos la vida perfecta allí donde hay menos consciencia". "Ei deseo de una virtud que razona no es razonable" (V. de P., 439). $Y$ es que la conciencia es búsqueda y el Superhombre es un resultado.

El Superhombre tarmpoco significa la ignorancia o desatención del "mundo pequeño", cuya cuidadosa consideración es antes bien señal de que se prepara esa fuerte especie de hombres que lo produce. Clima ,habitación, alimentación, matrimonio, recreo, "lo que hasta ahora fué despreciado es puesto por nosotros en primera línea".

Pese a todo lo que Nieizsche nos dice contra el "progreso" de la "civilización" (buena parte de ello tomado de su maestro Schopenhauer) habría una interpretación nietzscheana de la misma que, desde cierto aspecto, la justificaría y en la que la Sobrehumanidad aparecería como consecuencia más o menos previsible:

La justificación ciel mal como merecido, en la hipótesis de la moral re:igioso - y toda moral irreligiosa es filosóficamente una inmoralidad para Nietzsche - es un resagó del miedo deh primitivo que intervino en la formación de las creencias religiosas, pero ta historia de la civilización es la de la disminución déeste niedonal acaso, a lo incierto, a lo imprevisto, sinćnimos del mal. Con el crecimiento de la civilización, el sentimiento de la iey y el cálculo de lo previsible viene a ser tan grande que aparece cierto gusto por el azar, por lo incierto y lo imprevisto, así sea terrible: este es el pesimismo de la fuerza que goza del mal "puro y crudo" encontrando que "desprovisto de sentido es más interesante". Si antes el hombre necesitaba de Dios y desde El, el mal debía justificarse, ahora el mal es lo requerido y desde él es Dios quien necesita de justificación. Va'e decir este mundo cambiante e incierto es vigorosamente afirmado como el más alto posible. (V. de P., 1019). Esta, suprema afirmación del mundo y de la vida caracterizan al Superhombre.

Todo bien no es sino un mal hecho útil. Cuanto mayor mal vea una civilización, más baja estará, pues ese mal es expresión de un temor, esto es, de una debilidad. ' $Y$ ' en verdad justos y buenos ¡Muchas cosas hay en vosotros que mueven a risa y sobre todo vuestro temor de lo que hasta el presente ha sido llamado demonio" (Zarathustra, II, 
21). Los hombres y pueblos más desarrollados toman las cosas más terribles - las pasiones más violentas entre ellas -- a su servicio, es decir que hay muy poco "mal" para ellos.

No es que el Superhombre haya de carecer de "mala conciencia", sino que la tendrá para lo contrario de lo que la despierta en los hombres modernos, herederos de la "vivisección prehistórica del alma. Ya no lo natural "el pecado original", provocándola, sino "todas las aspiraciones al más allá contrarias a los sentidos, a los instintos, a la natulaleza, al animal en una paiabra, todo ideal enernigo de la vida, todo ideal que ca. lumnia al mundo" (Genealogía, II, 24). "Este hombre redentor, del gran amor y del gran desprecio", "vencedor de Dios y de la nada" "os menester que venga algún día". (Genealogía, II, 24).

Por esta terribilidad enseñoreada es que nos dice aquello de que lo terrible forma parte de la grande. Rechazado y superado todo hedonismo de la figura y acción del Súperhombre queda sólo la alegría dicnisiaca que es precisamente una superación de lo terrible por la paradojal, potente afirmación de vida que se lortalece y exalta por su medio. Por otro lado, de todo sufrimiento sale el sobrehumano más pleno y más poderoso y más capaz de amar. Las virtudes amables - a las que Nietzsche personalmente guardaba la mayor estimación - no tienen lugar que ocupar en el alma del sobrehumano.

Si por un lado es necesario trasmutar valores para provocar el advenimiento del «Superhombre,inporliotro,élemismo será llevado por su fuerza e independencia a crear y darse e imponer sus propios valores. Tendrá así también esta máxima cualidad, que correspondía también al hombre superior $y$ por lo tanto posibilidades negadas al hombre reli gioso.

Dentro de la posición -- afirmativa en la vida ascendente, negativa en la vida decadente - que se adopte ante la vida general, el Superhombre representa la máxirna afirmación posible de la existencia. La piedra de toque para probarla la encuentra Nietzsche como es sabido en la idea del retorno: la existencia, tal cual ha sido vivida, con absoluta identidad de circunstancia volviendo por toda la eternidad. Billones, trillones de años entre la muerte y el próximo nacimiento que precisamente por su desmesura equivalen a nada. Quien acepta esto, quien dice ¡Ś́! a esto, quien lo ama y desea con todas sus potencias, ese es el más rico, el más vivo, el más alto, ocupa el ápice de la vida ascendente; tiene el más auténtico y completo "amor fati". En cambio la vida que quiere un mundo diferente, un trasmundo de felicidad después de esta única existencia pasajera, o la que aspira al nirvana, eter- 
no sueño sin ensueños, más allá de la rueda de nacimientos y muertes - más sencillamente a la nada, revela su inópia por estos mismos deseos. Las almas decadentes, en el fondo nihilistas, no podrían soportar el pensamierto del retorno que sirve para colocar a los hombres en uno I otro de los dos grandes tipos morales.

Para los debilitados el retorno se aparece en última instancia como la eternidad de la nada, del sin sentido; para los poderosos es la del sentido que ellos otorgan a las cosas, que ellos "ponen". que ellos son. El retorno sustituye a la metafísica y a la religión en el pensamiento de Nietzsche (V. de P., 462). El filósofo espera de él notables efectos educativos de disciplina y selección de una especie superior de hombres.

El Superhombre es un verdadero salvador de todo lo que ha ocurrido en su vida personal y en la vida del hombre en general; las salva, las redime, queriéndolas. Es el salvador de la voluntad cuya pena más escondida conoce: "fué", esta es la pena oculta, esta es la impotencia de la poiencia ciue es la voluntad. Querer que el "fué" vuelva a ser es salvar la voluntad. "Todo lo que fué es fragmento y enigma y espantosa casualidad, hasta tanto que la voluntad creadora añada ¡Pero si es así como yo lo quería!. Hasta que la voluntad creadora añada: ¡Pero es así como yo lo quiero! ¡Así lo querré! (Zarathustra, II, 20). "La cuestión quieres esto una vez más y en número infinito de veces pesaría sobre todas Gusacciones de unas manera formidable. Cuanto tendrías entonces que amar la vida y amarte a tí mismo para no desear otro cosa sino esta suprema y eterna confirmación" (Gay Saber, 342). El retorno explica también la importancia de las "virtudes afirmativas" en la moral nitezscheana.

Si desde el punto de vista de su pasado individual, que como un hecho dentro del ciclo cósmico, implica todo el ciclo cósmico, el Superhombre puede actuar "hacia atrás", su voluntad creadora tiene también otra acción hacia atrás: la reconstrucción del pasado histórico desde su nueva tabla de valores. 'Pues la historia sabe tener una elocuencia siempre nueva para cada época" (V. de P., 974). Todo grande hombre posee una fuerza retroactiva, a causa de ól toda la historia es puesta otra vez en la balanza y mil secretos del pasado salen de su escondite para ser iluminados por "su" sol. Es imposible preveer todo lo que será aún la historia. El pasado quizá permanezca aún completamente inexplorado" (Gay Saber, 34). 


\title{
PALARRA EPILOGAL
}

\author{
"Yo no volveré entre vosst:os hasta que to. \\ dos hayáis renegado de mí. \\ En verdad hermanos míos: entonces buscaié \\ con otros ojos mis perdidas ovejas; entonces \\ os amaré con otro amor". \\ (Zarathustra, I, 22).
}

"The most contradictory tendencies of thought have at all times had this is common, that they professed to know already what good and evil are" "That this believe was futile is one of the most recent discoveries; we have to thank Nietzsche for the first clear statement of it" dice Ni Hartmann (Ethics - I, V, b), reconociendo el mérito de nuestro filósofo en este respecto. Y es por ello que, lomando una comparación usada por el mismo Nietzsche lo hemos llamado "El Copérnico moral". El presunto descendiente de los polacos condes Nietzky admiraba a la aristocracia polaca por el derecho de veto concedido a los nobles en sus asambleas, así el noble Copérnico vetaba una concepción cosmológica y así el noble Nietzsche veta una concepción ética.

$\mathrm{Si}$ no es ilícitolmedir la Gimportancia detuntfilósofo por su fecundidad, la del granJsolitario de Sils Moríanfesulta „así bastante destacada. Todo lo que se ha hecho en Etica en este siglo de más importante resulta siempre, en algín aspecto, cercano a él. Aunque se rechacen a veces muchas de sus apreciaciones, se le reconoce el haber llevado el pensamiento hasta la mayor intimidad del problema ético.

Una elevada conciencia intelectual, - que no es tampoco para nuestro pensador sino una conciencia moral sublimada - obliga, sin embargo, a tratar el problema moral extramoralmente. Por eso, para Nietzsche, moralista es sinónimo de innoralista y antípoda de "predicador de la moral". De su posición extramoral resulta un hallazgo extramoral: No existen los hechos morales - como en general no existen los hechos - sino interpretaciones de los mismos.

Se destaca también el que haya puesto en general el problema axiológico en el centro de la especulación filosófica. Y es que si la moral ocupaba el lugar central entre los órdenes de valores, problematizarla era problematizar toda la axiología.

Fl conocimiento llega - y a veces hasta demasiado pronto - al momento en que la "razćn se muerde su propia cola", pues la volun- 
tad de conocer vale sólo como la de reconocer, como la de recoger lo antes introducido - recoger se llama ciencia, introducir arte y religión, dice Nietzsche - y entonces es que las funciones intelectuales provocan escepticismo y aún, en el caso de Nielzsche, nihilismo. Pero por otro lado - la salvación viene de la voiuntad - se halla la posibilidad de introducir interpretaciones que otorgiten sentido.

Las jerarquias de los valores en estas diversas interpretaciones son las "iablas de valores". Nietzsche veía en la reinante en su tiempo a la moral en primer lugar, precisamente a la morai que había terminado en una pe!igrosa contraposición a la vida; por ello es que propone y él mismo intenta - colocar el arte en primer lugar. Con esto se habrían trasmutado todos los valores.

De allí que actuando en sonsecuencia, en lugar del alma, concepto religioso de :anta signifícación moral, nos hable del "hilo conduclor del cuerpo" de gran valor estético; contra la veracidad, exaltada por la moral y que Nietzsche justifica sólo en unos pocos casos como "lujo, refinamiento, vicio", ia divinización estética de la apariencia que había emprendido ya desde su "Orígen de la Tragedia": El mundo del hombre es así un mundo creado "por el artista, por el poeta, por el Dios hon!bre". Y contra el pensar abstracto, posible en las valoraciones morales, nos habla de la importancia de la imagen en el pensamierito, de la que es presencia en el espiritul "del "tozudamente real" "el cuerpo y sus ser:tidos, de aque!la en la que contraen verdadero matrimonio místico los sentidos y el espíritu.

Es el arte donde encuentra el gran instrumento de sublimación, en él las pasiones sin debilitarse se espiritualizan y embellecen. Es con él y solamente con él que podemos hacer una guerra inteligente a las pasiones: no para destruírlas sino para utilizarlas y hacerlas servir en provecho de nuestra elevación.

Hay algo que Nietzsche no discute, ni quiere discutir y piensa que no se debe discutir, un como axioma suprarracional - el contrario al de la posición de Schopenhauer - la vida misma. Y Nietzsche la ve en peligro, acechada por la nada, por esa nada escondida en la intimidad del hombre moderno que no se atreve a mirar a sí mismo, oculta tras la incredulidad en valoraciones que, sin embargo, se mantienen. En las instituciones modernas aparece una gran confusión de valoraciones diversas cuyo análisis muestra este gran vacío interior. Nietzsche que lo descubre nos quiere salvar de él. $\mathrm{El}$ arta le parece más cercano a la vida que la moral. 
¿Cómo se conoce una vida que se afirma a sí misma? En que se requiere a si misrna, en que se querría a sí misma una y otra vez, en que querría el eterno retorno de sí misma. Contra algunas interpretaciones que consideran la doctrina del Eterno Retorno como una filoscfía de la historia nos hemos permitido señalar que no sólo no lo es, sino que puede conciliarse con una filosofía de la historia irreversible. Los tiempos diferentes posibilitan la conciliación: teniendo el hombre aproximadamente medio millón de años sobre la tierra, la posibilidad de la repetición exacta de los mismos acontecimientos dentro de algunos tillones de años no puede valer como un hipótesis histórica.

A propćsito del retorno debemos mencionar como el "pathos" de Nietzsche es contrario al de los estoicos que tenían la misma creencia, en los que provocaba más bien una como altiva resignación. Es que en nuestro filósofo el retorno se sentía más bien desde el punto de vista de la proyección al futuro de todos nuestros actos, lo contrario de una resignación fatalisła.

Pues, si bien en Nietzsche el determinismo aparece de su cosmogonía, desde un punto de visia práctico, en cuanto nos enseña como las verdareramente virtuosas las acciones nuestras, las reveladoras de nuesira más intima personalidad - le parece que deben serlo hasta tal punto que en el Zarathustra y en "Más allá del bien y del Mal" nos aconseja que no denominemos de algún modo a nuestra virtud para no vulgarizada - por ser de la Voluntad de Poder no aparece ninguno de los efectos deprimientes que Gfounas veces derivan del determinismo.

"¿Qué es la libertad?. Tener la voluntad de la responsabilitad personal" (Crepúsculo IX, 38). "¿Cómo se mide la libertad tanto en el individuo como en el pueblo?. La medida de la resistencia que debe ser superada, de la fatiga que cuesta mantenerse arriba". Y N. Hartmann, por ejemplo, ha justificado esta reducción de Nietzsche de la libertad al poder, aunque desde un punto de vista diferente al nietzscheano. (Ethics, III, 20).

Pero el "creacionismo axiológico" ha sido muy combatido por la filosofía contemporánea, entre otras cosas porque el filósofo propiamen. te tal encuentra su importancia reducida casi a la de un botánico de la filosofía, notablemente disminuida con esta doctrina. Nietzsche abre las puertas para otra clase de hombres y otra clase de filósofos a los que el porvenir, como en el caso de los de tipo nitezscheano, o la poesía, como en el caso de Goethe, o el poder como entre los gobernantes de la "República" platónica, les den otra fisonomía. Hay la conser- 
servación de una "especie" que se defiende, en la inaceptación de la capacidad humana de creación de valores y tablas de valores.

$Y$ contra la creencia en que con el creácionismo abre las puertas al caos tengamos en cuenta que Nietzsche piensa en construcciones de tal naturaleza que duren muchos milenios - cien mil años llega a decir en una oportunidad - el problema es pues el de un creacionismo axiológico que llegada la cima de la sobrehumanidad sirviera para muchos milenios más. Si el hombre tiene menos de diez mil años de historia, "a priori" sociales que traten de durar cien mil años no deben considerarse como provocando la anarquía en el campo axiológico. Pero Nietzsche ha encontrado que el modo de hacerlos valer - en el caso de las Leyes de Manú, por ejemplo -es hacerlos pasar como mandamientos divinos. Ahora bien ¿es indispensable la mentira sobre el origen para asegurar la duración de las tablas de valores? ¿Podríamos encontrar un hombre tan alto y notable que pudiera sin ninguna referencia a otro mundo imponet sus valuaciones por cientos de milenios?: Nietzsche nos ha hablado de un "Vencedor de Dios y de la nada".

$\mathrm{Sin}$ embargo de lo anterior, el mismo Nietzsche a veces parece decirnos que sólo ha querido servir a quienes ha atacado. Pero se ha dado excesiva importancia a las frases en que ha declarado esto. (Por ejemplo A. Stern): "Nosotros los inmoralistas ¿Hacemos daño a la virtud?. Tan poco comol los anarquistas a los príncipes. Solamente desde que se disparó contra los príncipes se sientan estos en el trono por derecho propio. Moraleja: Se debe disparar contra la moral" (Crepúsculo I, 36). Y no se puede negar que "la ética real" de este sigla ha aprovechado del atentado, uno de sus más eximios representantes - Nietzsche católico" ha sido llamado - es un "príncipe" que se ha apresurado en agradecer al anarquista.

Como hombre de su siglo se nos aparece Nietzsche cuando al atacar el problema moral comienza por hacer una historia de los sentimientos morales. Contra un punto de vista metafísico, un punto de vista histórico. Si "lo incondicionado pertenece a la patología", a lo condicionado pues y a su proceso.

La prehistoria de que habla es, no sólo la de la moral, sino la de la razón misma: Como ha aparecido la moral en el hombre y "como se ha formado la lógica en la cabeza del hombre". Las horribles costumbres que han terminado por proporcionar una miaja de razón le sirven contra Schopenhauer para probar la importancia del dolor, de todo el mal que han costado las cosas buenas: Fuerzas descomunales, terriblemente reprimidas, al chocar contra sí mismas han producido los 
mejores de los rasgos humanos. La culpa ante Dios por el pecado orinal en el cristianismo es una salida para la inmensa presión interior. Pero la imposibilidad cada vez mayor de la creencia en este Dios por obra del desarrollo del sentido de la veracidad debido al propio cristianismo, deja esas fuerzas ya sin ningún empleo, en lucha contra sí mismàs, destruyendo sin posibilidades de una salida. La nada, el sin sen. tido, el más macabro de los fantasmas acecha al hombre. Nietzsche llega a decir: "Nada es verdad, todo está permitido"; pero este es un momento de desesperación, de nihilismo al que sigue después otro de creación de la verdad por la mayor de las fuerzas, por la más espiritualizada de las fuerzas: por la del filósofo, el creador de valores.

No denuncia, como se pudiera creer, la labor de las castas sacerdotales como maléfica: aunque debilitó al hombre al interiorizarlo volviendo a la vida sobre sí misma en el espíritu, por esto se abrieron posibilidades que, al ser heredadas y desarrolladas por una voluntad superior, determinarían una mayor multiplícidad. Y la mayor multiplicidad organizada es criterio nitezscheano Ael aumento de vida, es decir el valor por excelencia.

La voluntad de conocer concluye en la nada: el descubrimiento del primer Copérnico y la doctrina de la subjetividad de las cualidades sensibles, resultado de la matemaiización de la naturaleza, nos dejan un mundo cada vez máspáljdó en cl que el hombre zparece cada vez más excéntrico. La permanencia de las antiguas creencias se hace, por otro lado y en parte por" estas mismas circunstancias, cada vez más forzada, aunque no se abandone del todo -- Dios ha muerto, pero su sombra sigue llenando la caverna, anota Nietzsche - . Es el acosmismo, expresićn del nihilismo: el hombre ha perdido el hogar que era el universo. La excesiva valoración de sí que resultaba de la concepción de su destino en la docirina cristiana - el aristócrata arruinado no quiere trabaiar - le hace rechazar esta descomunal pérdida de valor: El humano no aceptz vivir en este país extranjero.

Si con Dios y las categorías que formaban el "mundo verdad" este mundo aparente, el de los colores y los sentidos resultaba desvalorado, el hombre, al perder su gran esperanza metafísica y ante la vaciedad de su contorno, resulta enfermo de nada aunque negando que este sea su mal. Nietzsche médico y taumaturgo, quiere, después de diagnosticar el mal, que el mal se declare para ofrecernos como talismán curativo una "llave": la voluntad de poder.

La Voluniad de Poder es un nombre, una "clave" nos dice Nietzsche. Si nos parece aceriada la problematización de la ética y aún el crea- 
s:ionismo axiológico - así la ética y en general, la filosofía contemporánea, haciéndose una vez más expresión de ese espíritu semisacerdo. tal que Nietzsche tanto combatió, hayan seguido por otro camino, el de siempre (las "tablas de valores" han devenido el "reino de los valores") - la clave nietz.scheana no nos gusta, con esa llave se han abierto compartimientos de la historia que hubiéramos preferido tuvieran la seudo-realidad de las ucronias. La "Voluntad de Poder" ha sido la isla de las aventuras de Simbad el marino: cuando se hizo fuego sobre ella, se hundió, pues se trataba de una enorme ballena.

El fuego de una espantosa conflagración ha hecho hundirse la ballena de la voluntad de poder. Estamos con la incitación del aficionado a las "travesías" éticas, pero al piloto queremos contradecirle: ¡No!, ¡No es una isla!

Queremos otra llave para el futuro y para nosotros mismos. La vida y la tierra americanas nos hablan con un lenguaje más maternal y esa maternidad es más sonriente, más dulce. Nuestros dioses no son Odines, sólo en un caso se han llamado Huiltzipochtli y a menudo Quetzalcoatl o Wiracocha. Nuestro sentido de la tierra, más cercano al espíritu, quiere otra llave de su Vulcano americano. Con tierra americana y en el crisol de nuestra esperanza fabriquemos la llave que dará sentido a nuestro presente y nos abrirá las puertas del porvenir.

Crecimiento vale decir elevación, sí, esto lo queremos, pero si el Superhombre es la gran síntesis queremos que reuna la conservación a la elevación: queremos la dufación de lo más elevado. Una inesperada nada en su senfido más literaleproporgionada también por la ciencia, nos amenaza; El Superhombre, vencedor de la nada, tiene que vencer también esta nada.

Mejor que el nombre de Zarathustra a la innombrable guardemos de él, su amor por ella y el reconocimiento del derecho de los más elevados a dar nombres.

Y sin embargo de rechazar el papel decisivo de la Voluntad de Poder, recibamos de la ética nietzscheana sus valiosísimas sugestiones. Una ética de la grandeza resulta conveniente en tiempos - los nuestros -. de empequeñecimiento del hombre. 


\section{BIBLIOGRAFIA}

Obras completas de Federico Nietzsche,

Ed. Aguilar. - Trad. Ovejero y Maury.

T. I. "El Origen de la Tragedia" y las Obras póstumas de 1869 a 1873.

"II. "Consideraciones Intempestivas".

"III. "Humano, demasiado Humano".

"IV. "Aurora, Reflexiones sobre los prejuicios morales",

"Una Ojeada sobre el presente y el porvenir de los Pueblos".

"V. "El Eterno Retorno" - "El Gay Saber".

"VI. "Así Hablaba Zarathustra".

"VII. "Más allá del Bien y del Mal".

"Genealogía de la Moral" - "Los Pueblos y Patrias".

"VV. "La Voluntad de Dominio" (Ensayo de una trasmutación de todos los valores).

"IX. "El Ocaso de los Idolos" - "El Anticristo".

"Ditirambos dionisiacos"..

" X. "Arte y Artistas" — "El Caso Warner" — "Nietzsche contra Warner" - "Ecce Homo".

" XI. "Tratados Filosóficos contemporáneos de Aurora y El Gay Saber".

" XII. Fragmentos de "Filosofía General".

"La Derniére Philosophie de Nietzsche". Charles Andler.

"La Jeunesse de Nierzsche. Charlesl Ándler.verso"

"La Maturité de Nietzsche. Charles Andler.

"Nietzsche ", H. Lefebvre.

"Frederic Nietzsche", Lou Andrees. Salomé.

"Nietzsche ", D. Halevy.

"Correspondencia " - F. Nietzsche.

"La Philosophie de Nietzsche", - Lichtemberger.

"El Pensamiento Vivo de Nietzsche", - H. Mann.

"Leyendo a Nietzsche", - E. Faguet.

"Schopenhauer y Nietzsche", - Simmel.

"Federico Nietzsche ", - Mariano A. Barrenechea.

"Federico Nietzsche". - Fouillé.

"Nietzche ", - A. Pfänder, (en "Los Grandes Pensadores).

"Nietzsche et la Philosophie de la Violence du Vingtieme Siecle", - Alfred Stern.

"Frederic Nietzsche", - Roberty. 
"Nietzsche y los Judíos, -- Richard Lonsbach.

"Nietzsche Dicnisiaco y Asceta", - E. Molina.

"Nietzsche " (un ensayo sobre el radicalismo aristocrático"), - Brandes.

"Nietzsche et la Reforme Philosophique", - Gaultier.

"Etica ", - M. Scheler.

"Esencia y formas de la Simpatía ", - M Scheler.

"Ethics", - N. Hartmann.

"Etica ", - E. García Maynez.

"Ser y Tiempo", - Heidegger. Ttra. José Gaos. (inédita).

"Existencialismo y Esencialismo ", - José Gaos.

"Las Ideas de la Filosofía", - José Gaos - F. Larroyo.

"El Sentimiento de la Vida Cósmica ", - M. Ibérico.

"Historia de la Filosofía ", - A. Messer.

"Historia de la Filosofía", - Will Durant.

" Historia de la Filosofía ". - Von Aster.

"La Filosofía de Enrique Bergson", - M. Iberico.

" El Sentimiento Trágico de la Vida ", - Unamuno.

"El Crepúsculo de los Filósofos", - G. Papini.

"La Agonía del Cristianismo", - M. de Unamuno.

"La Vie de Jesús", - Renán.

"Gorgias", - Platón.

"Sociología ", - Antonio Caso.

"Psicología ", - Honorio Delgade y Mariano Ibéticoas 